Estudios Constitucionales, Año 14, № 2, 2016, pp. 263-304

ISSN 07180195

Centro de Estudios Constitucionales de Chile Universidad de Talca

"El derecho a la verdad"

Gerardo Bernales Rojas

\title{
EL DERECHO A LA VERDAD*
}

\author{
THE RIGHT TO THE TRUTH
}

Gerardo Bernales Rojas ${ }^{* *}$
Universidad de Talca
gbernalesr1@gmail.com

RESUMEN: El Derecho a la Verdad es un derecho relativamente reciente, que, por lo mismo, no tiene un reconocimiento expreso y formal, más allá de la Resolución $N^{o} 9 / 11$ de la ONU; pero que ha tenido una evolución y progresión permanente y muy fuerte por la vía jurisprudencial y doctrinaria, lo que le otorga un estatus indiscutido como derecho fundamental autónomo, el que ya tiene en la práctica. El presente trabajo tiene por objetivo explicar y fundamentar esta realidad.

ABSTRACT: The right to truth is a relatively recent right. For this reason, it does not have an explicit and formal acknowledgment beyond the 9/11 ONU Resolution. However, the right to truth has been in permanent evolution and progress, in particular through the jurisprudential and doctrinaire paths, which warrant an undisputed status as a fundamental autonomous right, which the right to truth already has in practice. This work aims to explain and justify this reality.

Palabras Claves: Derechos Fundamentales, Debido Proceso, Derecho a la Verdad, Derecho a la Investigación, Derecho a la Reparación.

KEYWORDS: Fundamental Rights, Due Process, Right to Truth, Right to Investigate, Reparation Right.

\section{INTRODUCCION}

El desarrollo de la doctrina de los derechos humanos tiene hoy diversas fuentes, lo que le permite un progresivo avance en la cobertura de las diversas manifestaciones de los derechos fundamentales. Sin embargo, el derecho a la verdad, no obstante su constante y continuo reconocimiento en la jurisprudencia de la Corte Interamericana de Derechos Humanos ${ }^{1}$, como así también de manera expresa en la Resolución No 9 /11 de las Naciones Unidas, no aparece reconocido como un

\footnotetext{
* Trabajo recibido el 18 de enero de 2016 y aprobado el 7 de septiembre de 2016.

** Abogado de la P. Universidad Católica de Chile (1996), Magíster en Derecho con Mención en Derecho Público por la U. de Chile (2000), Juez del Primer Juzgado Civil de Talca y profesor conferenciante en la Facultad de Ciencias Jurídicas y Sociales de la U. de Talca, en las cátedras de Derecho Político, Derechos Fundamentales y sus Garantías, y Derecho Procesal. Candidato a Doctor en Derecho por la Universidad de Talca.

1 En adelante, Corte IDH.
} 
derecho fundamental autónomo de forma expresa, ni en los tratados internacionales sobre derechos humanos ni en cartas fundamentales. Constituye esta situación, a nuestro juicio, una omisión que debe ser saldada, aunque algunos entienden que no hay omisión por cuanto contemplan el reconocimiento de dicho derecho dentro del derecho al debido proceso ${ }^{2}$, lo cual nos parece insuficiente.

A nuestro entender, hoy se reúnen todas las condiciones y requisitos para reconocer el derecho a la verdad como un derecho fundamental autónomo, faltando sólo el reconocimiento formal y expreso, tanto en convenios internacionales como en las cartas fundamentales de los Estados.

En algunos casos, la jurisprudencia de la Corte IDH lo trata como un derecho subsumido en el derecho al debido proceso ${ }^{3}$. Pero no podemos olvidar que uno de los efectos traumáticos más frecuentes que dejan el paso de los gobiernos autoritarios, como también las crisis humanitarias de cualquier origen o causa, es la incertidumbre del "qué pasó con las víctimas", el "cómo y por qué

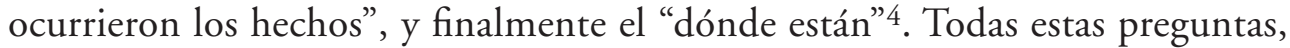
reiteradamente oídas respecto de los familiares y víctimas de violaciones de derechos humanos, sin duda son entendibles y lógicas, y ya casi nadie discute que merecen una respuesta institucional, una respuesta que debe venir del ámbito jurisdiccional, de manera que satisfaga convincentemente esta inquietud, y también es una respuesta que toda sociedad civilizada debe tener para el registro de su historia 5 , más allá de cualquier solución política que quiera darse; esa respuesta, que sólo da el ámbito jurisdiccional, es el restablecer la verdad de lo ocurrido por medio de la prueba de los hechos alegados, como expresaba Bentham en su arte de administrar pruebas ${ }^{6}$.

Sin embargo, el paso del tiempo y la desaparición de los actores de los procesos que aparecen como posibles victimarios ${ }^{7}$ van provocando que la adhesión a

2 Salmón y Blanco (2012), pp. 42-43.

3 EsPejo y Leiva (2012), pp. 389-397.

4 En las situaciones de las desapariciones forzadas de personas, que constituye el caso más grave de vulneración de los Derechos Humanos.

5 Convención Americana de Derechos Humanos, Comentarios (2014), p. 634.

6 Bentham (1847), pp. 55-56.

7 La dilación indebida de los procesos investigativos o el no inicio de los mismos mientras duran las crisis humanitarias provocan que, finalmente, cuando los procesos judiciales, con garantías reales de justicia, se inicien, muchos de los victimarios ya han fallecido, o bien han huido, o, sencillamente, se encuentran en estado de avanzada edad, o con enfermedades graves y crónicas, haciendo que aparezcan frente a la socie- 
este llamado de justicia humanitaria y las exigencias de la verdad se transformen, para el resto de la comunidad, en sentimientos de aparente abuso del derecho por causas políticas y no en un imperativo de justicia social; se pasa a ver en la exigencia de verdad un anhelo de venganza privada y partidista y no una exigencia cuya fuente es la dignidad de la persona. Así, ocultado bajo un velo mediático propagandístico ${ }^{8}$, la necesidad de buscar y reconocer los hitos fundamentales de una verdad histórica (y dramática) que todo pueblo debe conocer, se transforma para la opinión pública en un tema político y, por lo mismo, en un tema transable, lo que atenta contra el carácter de derecho fundamental o humano, que pretendemos demostrar respecto del derecho a la verdad.

En este contexto, y agravado por el paso del tiempo sin justicia, es que se transforma a los victimarios de antes, con frágiles figuras ancianas que nada reflejan ni recuerdan de su crueldad pasada, en víctimas de hoy, lo que provoca frente a la comunidad una imagen e impresión de incredulidad y muchas veces hasta de duda respecto de las graves situaciones y hechos provocados a sus víctimas y familias en el pasado, lo que constituye sin duda un nuevo atentado contra los derechos fundamentales de la víctima.

En efecto, todo esto no hace más que provocar una triple victimización de los afectados y sus familias, quienes, primero, sufren el drama del crimen; segundo, luego deben relatar sus experiencia traumáticas en los procesos judiciales donde vuelven a vivir los detalles ante fríos e impersonales tribunales, sin el amparo psicológico que crímenes de esta naturaleza ameritan, y, tercero, finalmente, al transcurso del tiempo sin tener resultados judiciales ni la obtención de una verdad relativamente cercana a la realidad, se le suma la pérdida de la empatía social por el "cansancio" que sus reivindicaciones provocan, causando en nuevas generaciones

dad como ancianos débiles y desvalidos, y no como los criminales de guerra que son, lo que los transforma mediáticamente en personas que no ameritan tanto castigo ni repudio social, e incluso se les ha llegado a considerar "aparentes víctimas de la venganza", haciendo que los procesos de investigación por crímenes de lesa humanidad pierdan adhesión ante la opinión pública frente a estos "rostros desvalidos" que presentan los victimarios.

8 "Los regimenes represivos reescriben deliberadamente la historia, negando las atrocidades para legitimarse. La búsqueda de la verdad contribuye a la creación de un registro histórico que impida esta clase de manipulación. Al dar más información a las víctimas sobre los hechos sufridos (la suerte de los desaparecidos o la razón de que algunos grupos fueran blanco especial de la represión), puede ayudarles a cerrar esa etapa.

Las iniciativas de búsqueda de la verdad son muy diversas-incluyen leyes que garantizan la libertad de expresión, desclasificación de archivos o investigaciones sobre desaparecidos- y también conducen al establecimiento de comisiones de investigación no judicial, entre ellas las comisiones de la verdad." [ICTJ, Verdad y Memoria (2015)]. 
apatía y desinterés, y después desencanto, desagrado y rechazo de sus causas que, siendo justas, pasan a un segundo plano por no haberse aclarado oportunamente.

Además, y a contrario sensu de lo ya señalado, tampoco resulta aceptado por la comunidad que los procesos concluyan con sentencias irracionales, o bien en decisiones políticas, fundadas en una precreencia de la criminalidad del acusado, pues deja de ser justicia y pasa a ser venganza, algo que ya advertía Kelsen que no debía ocurrir: "El castigo de los criminales de guerra debería ser un acto de justicia internacional, no la satisfacción de la sed de venganza" ${ }^{9}$, de tal forma que siempre el derecho a la verdad debe ser resuelto en sede jurisdiccional y con todas las garantías del debido proceso, especialmente en la fundamentación de la sentencia.

Éste es el contexto en el que el derecho a la verdad, reconocido reiteradamente en la jurisprudencia de la Corte IDH como parte del debido proceso ${ }^{10}$, adquiere una dimensión relevante en la construcción de una sociedad civilizada; no basta un sistema de represión que pretenda hacer justicia desde el ejecutivo, no bastan leyes que pretendan imponer soluciones negociadas, ni procesos que entreguen decisiones alegadas de la verdad de lo ocurrido; sino que toda sociedad requiere vivir en condiciones de justicia para ser aceptada y, como señalaba Rawls, “... las primeras virtudes de la actividad humana, la verdad y la justicia, no pueden estar sujetas a transacciones..."11. Es por ello que el reconocimiento de este derecho precisa que ya no sólo se le contemple como una parte del debido proceso, sino como un derecho fundamental autónomo, ubicado además dentro de los derechos sociales, resultando su reconocimiento una necesidad en las sociedades políticas modernas.

El derecho a la verdad es un derecho que ya tiene un camino desarrollado en su formulación como derecho fundamental autónomo. En efecto, con una primera mirada, podríamos señalar que se trata de un derecho actualmente en desarrollo

9 Kelsen (2003), p. 125.

10 Sentencia Corte IDH del caso Castillo Páez, 3 de noviembre de 1997, Serie C No 94, párrafo 90; Sentencia Corte IDH del caso Bulacio, 18 de septiembre de 2003, Serie C No 100, párrafo 114; Sentencia Corte IDH del caso de la Masacre de La Rochela, 11 de mayo de 2007, Serie C No 140, párrafo 219; Sentencia Corte IDH del caso Blanco Romero y otros, 28 de noviembre de 2005, Serie C No 128, párrafo 62; Sentencia Corte IDH del caso Contreras y otros contra El Salvador, 31 de agosto de 2011, Serie C No 232, párrafos 170 y 171; Sentencia Corte IDH caso Gomes Lund y otros (Guerrilha de Araguaia) con Brasil, 24 de noviembre de 2010, Serie C 219, párrafo 211; Sentencia Corte IDH caso Comunidad de Río Negro vs. Guatemala, 4 de septiembre de 2012, Serie C No 250, párrafo 194.

11 RaWls (1995), p. 18. 
progresivo y cuya normativa no resultaría totalmente vinculante, al decir de algunos autores ${ }^{12}$. Sin embargo, nuestro juicio, la realidad indica otra cosa, ya que existen, por ejemplo, las comisiones de la verdad establecidas en diferentes Estados, que han salido de situaciones de crisis políticas y sociales; también la Resolución No 9/11 de las Naciones Unidas y la abundante jurisprudencia y doctrina que tratan el derecho a la verdad como un derecho humano autónomo vinculante para los Estados; como, por ejemplo, lo señala expresamente la Corte IDH en el caso "Myrna Mack Chang vs. Guatemala" en el cual, en el párrafo 274, expresa que "La Corte ha reiterado que toda persona, incluyendo a los familiares de victimas de graves violaciones de derechos humanos, tiene el derecho a la verdad. En consecuencia, los familiares de las victimas y la sociedad como un todo deben ser informados de todo lo sucedido con relación a dichas violaciones. Este derecho a la verdad ha venido siendo desarrollado por el Derecho Internacional de los Derechos Humanos; al ser reconocido y ejercido en una situación concreta, ello constituye un medio importante de reparación. Por lo tanto, en este caso da lugar a una expectativa que el Estado debe satisfacer a los familiares de la victima y a la sociedad guatemalteca"13. Y en el mismo fallo cita la jurisprudencia ${ }^{14}$ en que fundamenta esta afirmación, de manera que hay antecedentes concretos y sólidos que indican o fundamentan la existencia y reconocimiento de este derecho, no sólo como un imperativo moral del Estado, sino que también como un deber jurídico capaz de restringir el ejercicio de sus poderes y a la vez obligarlo a actuar positivamente en favor de la obtención de la verdad.

Así surge el "Derecho a la Verdad", pero, al hablar de derecho a la verdad, estamos hablando de un derecho fundamental que se encuentra enmarcado, como ya se dijo, dentro del ámbito del debido proceso y las garantías judiciales, en

12 Fajardo (2012), p. 16.

13 Sentencia Corte IDH del caso Myrna Mack Chang vs. Guatemala, de 25 noviembre de 2003, Serie C No 101, párrafo 274.

14 Caso Trujillo Oroza. Reparaciones, supra nota 277, párr. 114; Caso Bámaca Velásquez. Reparaciones, supra nota 277, párr. 76. Véase, por ejemplo, United Nations Human Rights Committee, Quinteros vs. Uruguay, Communication No 107/1981, decision of july 21 st, 1983; Naciones Unidas, Comisión de Derechos Humanos, Subcomisión de Prevención de Discriminaciones y Protección a las Minorías, $49^{\circ}$ período de sesiones, Informe final revisado acerca de la cuestión de la impunidad de los autores de violaciones de los derechos humanos (derechos civiles y políticos) preparado por L. Joinet, UN General Assembly Doc. E/CN.4/Sub.2/1997/20/ Rev.1; Naciones Unidas, Comisión de Derechos Humanos, Subcomisión de Prevención de Discriminaciones y Protección a las Minorías, $45^{\circ}$ período de sesiones, Estudio relativo al derecho de restitución, indemnización y rehabilitación a las víctimas de violaciones flagrantes de los derechos humanos y las libertades fundamentales, Informe definitivo presentado por Theo van Boven, Relator especial, E/CN.4/Sub.2/1993/8. 295 Cfr. Caso Trujillo Oroza. Reparaciones, supra nota 277, párr. 114. 
términos del artículo $8^{\circ}$ de la Convención Americana sobre Derechos Humanos, por lo que se le vincula al acceso a la justicia, a las garantías judiciales efectivas y a la obligación de investigar; vinculación que existe, pero que no lo subsume dentro de ellos, pues tiene finalidades diferentes, $y$, al tener finalidades diferentes, también hay medios diferentes, lo que le da su autonomía.

De esta forma, se trata de un derecho que no tiene un reconocimiento unánime como derecho fundamental autónomo en la comunidad internacional, sin perjuicio de los particulares reconocimientos de informes, comisiones, consejos y resoluciones de organismos internacionales ${ }^{15}$, como también de la jurisprudencia humanitaria internacional, como lo expresa la Corte Europea de Derechos Humanos cuando, no obstante haberse declarado incompetente de conocer una causa basada en hechos anteriores a la adopción del Convenio Europeo de Derechos Humanos, "insta a las autoridades rusas a reforzar su colaboración para arribar a la verdad histórica"16, o la jurisprudencia local a través de fallos de tribunales constitucionales, como el de Perú, que reconoce el derecho a la verdad como un derecho nuevo ${ }^{17}$ que surge a partir de la configuración de tres elementos: la fundamentalidad del derecho que reivindica un derecho de un sector generalmente

15 Como ocurre con: la Resolución No 9 /11 del Consejo de Derechos Humanos de las Naciones Unidas de 24 de septiembre de 2008; Resolución AG/RES. 2175 (XXXVI-O/06) "El derecho a la verdad" de la Asamblea General OEA, punto sexto; ONU, Comisión de Derechos Humanos, Informe de la Oficina del Alto Comisionado de las Naciones Unidas para los Derechos Humanos, "Estudio sobre el derecho a la verdad", E/CN.4/2006/91, 9 de enero de 2006, párrafo 8; ONU, Comisión de Derechos Humanos, Conjunto de principios actualizado para la protección y la promoción de los derechos humanos mediante la lucha contra la impunidad, E/CN.4/2005/102/Add.1, 8 de febrero de 2005; CIDH, Informe de la Relatoría Especial para la Libertad de Expresión, El Derecho de Acceso a la Información en el marco jurídico interamericano, OEA/Ser.L/V/II, CIDH/RELE/INF. 1/09, 30 diciembre 2009, párr. 77; ONU, Consejo de Derechos Humanos, "Informe del Relator Especial sobre la promoción de la verdad, la justicia, la reparación y las garantías de no repetición”, Pablo de Greiff, A/HRC/21/46, 9 de agosto de 2012, párrafo 30; ONU, Comisión de Derechos Humanos, "Conjunto de principios actualizado para la protección y la promoción de los derechos humanos mediante la lucha contra la impunidad", E/CN.4/2005/102/Add.1, 8 de febrero de 2005; ONU, Consejo de Derechos Humanos, Informe de la Oficina del Alto Comisionado de las Naciones Unidas para los Derechos Humanos, "El derecho a la verdad", A/HCR/5/7, 7 de junio de 2007, párrafo 89; OEA, Consejo de Derechos Humanos, Resolución No 12 /12 del año 2009, sobre "El derecho a la verdad". También en forma implícita en la Declaración Americana de Derechos Humanos, artículos IV, XVII y XXIV; en la Convención Americana de Derechos Humanos, artículos 8 y 25; en el Primer Convenio de Ginebra, de 1949, artículo 32; en el Convenio Europeo de Derechos Humanos, artículos 2, 3, 5, 6 y 8, o en la Carta de Derechos Fundamentales de la Unión Europea, artículos 47, 49 Nos. 2, 42 y 44.

16 Tribunal Constitucional de Chile (2015), pp. 432-433.

17 Sentencia Tribunal Constitucional de Perú, 18/03/2004, "Caso Genaro Villegas Namuche”, rol No 24882002, párrafo 4, Nos. 13, 17 y 20. 
minoritario; el estado de no positivización del mismo, y el sustento principialista o de cláusula abierta contenido en la Constitución ${ }^{18}$. Todo lo anterior sin perjuicio de que ya en el Protocolo Adicional I de los Convenios de Ginebra de 1949 (del año 1977$){ }^{19}$ podemos encontrar los orígenes jurídicos del derecho a la verdad ${ }^{20}$.

Entonces, ¿es posible arribar a una verdad histórica o absoluta? Sobre esto, bastante discuten Taruffo y Cavallone ${ }^{21}$, sin embargo, no es el tema de fondo de esta investigación, pero sí lo es señalar la importancia de poder determinar qué se entiende por verdad en el proceso. Y, también, es necesario conocer esta verdad histórica como un aspecto determinante para poder responder a la pregunta de si el derecho a la verdad constituye un derecho humano o fundamental que debe ser reconocido o no.

Las respuestas a estas preguntas, que surgen en este tema, más allá del reconocimiento histórico que los pueblos requieren para entender su realidad y proyectar su desarrollo humano, social y cultural, se hacen necesarias para comprender, a la luz del derecho, lo relevante que es hacer respetar lo más sagrado de todas las personas: la integridad de su dignidad como ser humano, reconociendo a este derecho tanto en su dimensión individual, como colectiva ${ }^{22}$, y, por sobre sus vínculos con el derecho de acceso a la justicia, el derecho a un debido proceso, el derecho a un recurso o acción efectiva y eficaz, el derecho a la investigación y el derecho a la información, se trata de reconocerlo como un derecho fundamental autónomo ${ }^{23}$ y no sólo como un derecho subsumido dentro de alguno de los anteriores 24 .

En definitiva, el objetivo principal de este trabajo consiste en intentar demostrar el suficiente desarrollo normativo, doctrinario y jurisprudencial del derecho a la verdad, para reconocerlo como un derecho fundamental de carácter autónomo y social, toda vez que la hipótesis que sostenemos es que el desarrollo doctrinario y, especialmente, jurisprudencial, permiten considerar

18 Ávila (2012), documento electrónico.

19 En sus artículos 32 y 33. NAQVI (2006), p. 5.

20 Rodríguez (2009), p. 33.

21 Cavallone y Taruffo (2012), pp. 53, 65-67.

22 Convención Americana de Derechos Humanos, Comentarios (2014), p. 634.

23 Alto Comisionado Naciones Unidas, "Estudio sobre el Derecho a la Verdad”, pp. 30-31.

24 Como el derecho de las víctimas o sus familiares a obtener el esclarecimiento de los hechos, el derecho a la investigación (GARCÍA (2012), pp. 72-73), un aspecto del debido proceso o del acceso a la justicia. 
que el derecho a la verdad cumple con todos los requisitos para ser considerado como un derecho fundamental, que tiene una existencia independiente de los demás derechos a los que está vinculado, como el derecho a la investigación, el derecho de acceso a la justicia, el derecho a la información, el derecho a la reparación, entre otros, y que, por lo mismo, se justifica su reconocimiento formal y expreso dentro de los derechos sociales.

En este sentido, entenderlo como un derecho autónomo implica ir más allá de las garantías judiciales, toda vez que en éstas, justamente, lo que más se busca es proteger los derechos y garantías del imputado, y subsumir el derecho a la verdad en materia de derechos humanos dentro de ellas puede condicionar el valor fundamental de la verdad que, en este contexto, tiene una finalidad diversa, ya que en uno (proceso penal) se busca un proceso que garantice una sentencia justa, y en el derecho a la verdad (crímenes de lesa humanidad), más allá del resultado formal, que es la sentencia, está la obtención del bien jurídico deseado que es el saber qué pasó, como, cuándo y por qué, y eso, en materia de derechos humanos, puede tardar más tiempo que el aceptable en una investigación penal simple. Por estas mismas razones, el carácter social del derecho a la verdad se impone más allá de la seguridad jurídica y la justicia formal; la comunidad no puede dejar de saber qué aconteció en estos casos.

La metodología a utilizar en el presente trabajo es la formulación doctrinaria del llamado derecho a la verdad; la relación entre el concepto de "verdad" con la idea de derecho y de proceso. Asimismo, y a partir de la formulación doctrinaria del derecho a la verdad, mediante la determinación de su origen y contenido, realizaremos el análisis comparativo de cómo, desde el surgimiento de este derecho en el Derecho Internacional humanitario, se ha ido efectuando su reconocimiento, al menos jurisprudencial, en Chile.

\section{VERDAD, PROCESO Y DERECHO}

1.- Una primera pregunta que debemos hacernos es qué entendemos como verdad, y en este sentido la opinión de los autores es variada. Bonnier señala que "descubrimos la verdad (de algo) cuando hay conformidad entre nuestras ideas y los hechos del orden físico o del orden moral que deseamos conocer ${ }^{25}$ ". Pero esta verdad en abstracto, aplicada al proceso, no siempre tiene la misma lógica, Carnelutti señalaba que es imposible reconstruir la verdad de los hechos

25 BONnier (1869), pp. 5-6. 
tal como ocurrieron, verdad material, lo que hay en un proceso no es la verdad, es la fijación material de los hechos ${ }^{26}$. Por todo esto, Ferrer nos recuerda que se hablaba de dos tipos de verdades: hay una verdad material y una verdad formal; la primera está fuera del proceso y la segunda es a la que se arriba mediante la prueba de los hechos en el proceso ${ }^{27}$. Sin embargo, esta distinción se fue rechazando progresivamente porque, como señalaba Carnelutti, la verdad es como el agua: o es pura o no es verdad ${ }^{28}$.

De esta forma, podríamos responder a la pregunta de qué es la verdad diciendo que es un conocimiento certero sobre una realidad determinada. Como no es el objeto central de este trabajo, no ahondaremos mayormente en la definición de verdad y sobre este concepto muy básico, ya dado, expondremos algunas consideraciones.

La idea de verdad supone el acontecimiento de hecho respecto del cual surgen las conclusiones que van a expresarse desde el grado de conocimiento del mismo; desde el bagaje cultural y de informaciones que se tenga para interpretar el hecho; desde la cosmovisión que se tenga, e, incluso, desde la facilidad de expresión que tenga el intérprete de la verdad para relatar lo sucedido, todo lo cual necesariamente nos va a llevar a conclusiones diversas dependiendo de quién relate el hecho.

Existen varias teorías para comprender qué se entiende por verdad; por ejemplo, Gascón señala que lo primero a lo que debe atenderse es a si los enunciados de esa realidad o de la verdad a la que se ha arribado están en concordancia entre $s{ }^{29}$, es decir, existe verdad cuando los enunciados expuestos son coherentes entre sí. En segundo término, un enunciado no está justificado porque sea verdadero, sino que se entiende verdadero porque está justificado ${ }^{30}$. El problema se presenta cuando las justificaciones de un tiempo o lugar no mudan o no se dan en otro tiempo o lugar, entonces, lo que era verdadero, ya no lo es. Y, por último, hay verdad, cuando hay correspondencia con la realidad ${ }^{31}$; sin embargo, ello implica recurrir a los anteriores criterios, pues el primer enunciado se obtendrá

\footnotetext{
26 Carnelutti (1947), pp. 33-34

27 Ferrer (2005), pp. 61-64.

28 Carnelutti (1947), p. 33.

29 GASCÓN (2004), p. 55.

30 Wilemann (2014), pp. 69-78.

31 GASCÓN (2004), p. 70.
} 
del contraste empírico, y luego los demás requerirán del apoyo de la lógica con los primeros enunciados ${ }^{32}$.

La verdad, de esta forma, existe en cuanto el acaecimiento de un hecho concreto que viven los actores del mismo, pero el análisis, interpretaciones y conclusiones que extrae el tercero que lo observa o conoce, e incluso las propias partes, va a variar dependiendo de su visión o posición en el hecho, como ya se ha dicho. Pero lo que no puede discutirse es que sin verdad no hay justicia, ya que sin una verdad que fundamente una decisión, se trata de una decisión tomada sobre un sistema de arbitrariedades ${ }^{33}$; el tema está en señalar qué tipo de verdad se busca, y ella debe ser la verdad probada o acreditada en un proceso y que este proceso cumpla con los estándares y garantías mínimas que se exigen para su legitimación o validez.

2.- El proceso. Éste es un segundo elemento a conjugar. Chiovenda señala que "es el conjunto de actos coordinados para la finalidad de la actuación de la voluntad concreta de la ley (en relación a un bien que se presenta como garantizado por ella) por parte de los órganos de la jurisdicción ordinaria" 34 . Calamandrei señala que el proceso es una serie de actos coordinados y regulados por el Derecho Procesal, a través de los cuales se verifica el ejercicio de la jurisdicción ${ }^{35}$. Y Rocco señala que proceso civil es el "conjunto de actividades de los órganos jurisdiccionales y de las partes necesarias para el desenvolvimiento de la función jurisdiccional civil" 36 .

De esta forma, el proceso supone una forma de solución de conflictos de relevancia jurídica mediante una fórmula que implica la exposición de hechos a través de una demanda o acusación, y la contestación de la misma; y donde un tercero, el tribunal, resuelve finalmente, conforme a la probanza rendida. Surge así, a juicio de Taruffo, un problema en dos sentidos en relación a la verdad: el primero es si el proceso puede buscar o tener como objetivo el esclarecimiento de la verdad de los hechos, y el segundo es qué tipo de verdad es ésa ${ }^{37}$.

Si queremos un proceso con una sentencia justa, ese proceso debe estar basado en la veracidad de los hechos; y la verdad que se busca no es la absoluta, sino que

32 Coloma y Agüero (2014), pp. 90-92, 94

33 Ferrajoli (1995), p. 45.

34 Chiovenda (2001), p. 22.

35 Citado por BAilón (2004), p. 120.

36 Rocco (2001), p. 65.

37 TARUffo (2009), p. 95. 
la verdad procesal, que es una verdad relativa que dice relación con los hechos alegados y la probanza rendida puntualmente en el proceso ${ }^{38}$. Así lo decía Couture: “... porque probar es persuadir de la verdad de los hechos, de la misma manera que alegar es persuadir de la verdad de la tesis de derecho..."39.

El establecimiento de la verdad procesal, o judicial, va a quedar determinado según sea la capacidad de las partes de aportar las pruebas idóneas para acreditar sus dichos ${ }^{40}$, como también por la capacidad de lograr la convicción del tribunal acerca de la verdad planteada por la parte ${ }^{41}$. La única verdad, entonces, será la de la sentencia, y, sin embargo, aún cuando para llegar a ella han competido dos verdades particulares, la sentencia puede arribar a una tercera verdad, la que va a estar configurada por los hechos que cada parte probó, acogiendo en parte los hechos alegados por una de las partes, y acogiendo algunos otros hechos probados por la otra parte.

A partir de lo anterior no cabe sino preguntarse cuál es la verdad, entonces, en un proceso, si las partes alegan A y B, respectivamente, puede que el fallo resultante no sea ni A ni B, sino que sea " $A B$ ", constituido por una mezcla entre las verdades que $\mathrm{A}$ y $\mathrm{B}$ pudieron acreditar. En un proceso no se puede asegurar que se va a establecer una verdad absoluta, porque va a depender ya no sólo de los factores que indicamos en el párrafo segundo de este apartado, sino que además de la posibilidad de probarlos, como también de la capacidad y pericia de las partes, de que el aporte de esas pruebas se haga de manera oportuna y eficiente, lo cual, sin duda, agrega un grado más de dificultad a esta búsqueda de la verdad. Por ello, el derecho a la prueba para demostrar una verdad no es absoluto ni ilimitado, puesto que contiene limitaciones intrínsecas, como la pertinencia, la necesidad y la licitud ${ }^{42}$, y a la vez limitaciones extrínsecas, que dicen relación con los requisitos que las leyes establecen en el modo de proponerlas dentro de un procedimiento en particular ${ }^{43}$.

En doctrina, a lo menos hay tres corrientes en relación a la verdad. En una de ellas, Damaska expresa que el proceso tiene dos modelos, uno que tiene por

\footnotetext{
38 TARUfFo (2009), pp. 97-98.

39 Couture (1998), p. 65.

40 Bordalí (2009), pp. 284-290.

41 Montero Aroca (2007), p. 60.

42 Existen diferentes límites y principios que regulan la actividad probatoria, como la eficacia, licitud, unidad, necesidad, etc., entre otros. Devis (2012), pp. 13-25.

43 VAllespín (2002), p. 75.
} 
objeto alcanzar la verdad y otro que sólo busca la solución del conflicto jurídico ${ }^{44}$. En una segunda postura, Montero Aroca señala que en el proceso se busca una verdad objetiva, porque hay un interés público comprometido ${ }^{45}$. Mientras que en la tercera postura, autores como Hunter expresan que el proceso no tiene como objeto la búsqueda de "la verdad", sino la resolución de los conflictos jurídicos ${ }^{46}$, dentro de los cuales se establece una verdad procesal, o judicial, mediante una sentencia, la que tiene el mérito de dar certeza frente a la discusión de un hecho determinado y causar sus efectos para que el proceso concluya en "decisiones que puedan considerarse justas en tanto fundadas en la correcta aplicación de la ley y en la determinación verdadera de los hechos..."47, es decir, decisiones justas porque están fundadas en la ley y justificadas en los hechos acreditados conforme a la demanda, la prueba rendida y la norma legal. Esto último también lo afirman otros autores como Guilherme y Cruz, al señalar que la justa composición de la litis sólo se logra "por medio del descubrimiento de la verdad sobre los hechos versados en la demanda" 48 .

En relación a lo anterior, cabe hacer algunas precisiones. Primero, en cuanto a la diferencia que hay entre la búsqueda de la verdad y la convicción de la verdad $^{49}$; en efecto, no puede hablarse de conocer la esencia de la verdad porque ella es inalcanzable, no sólo en el proceso, sino que en todo aspecto de la vida humana, y no puede ser el juez un iluminado que la alcanza, por el solo hecho de ser juez; a lo que éste aspira es a lograr la convicción de lo que puede ser la verdad y es sobre ésta que dicta la sentencia. Así, la verdad alcanzada en el proceso parte de la base de que la verdad objetiva no puede ser alcanzada, y que lo que se logra es la convicción de lo que puede ser considerado verdadero. Aun si el juez tuviera facultades oficiosas para decretar prueba y lo hiciere, ello no lo hace para alcanzar la "verdad objetiva o material" 50 , lo hace para lograr sus propias con-

\footnotetext{
44 DAMASKa (2000), pp. 125-168.

45 Montero Aroca (2013), p. 237.

46 HunTer (2015), pp. 26-28.

47 Cavallone y Taruffo (2012), p. 66.

48 Marinoni y CRUZ (2015), p. 7.

49 Marinoni y Cruz (2015), p. 73.

50 Sólo a modo referencial, podemos ver que así lo ha señalado el máximo tribunal chileno: Sentencia de la Corte Suprema, causa rol No 11745-11, 5 abril de 2012, Primera Sala: Noveno: Que..., así, en estas situaciones, la probanza en análisis pierde su carácter de plena prueba por haberla excluido la ley respecto de los hechos que componen el objeto del proceso, porque inciden sobre derechos que él confesante no puede renunciar o
} 
vicciones de la verdad que se le está presentando ${ }^{51}$. La segunda precisión es que la definición o categorización de verdadero recae sobre el enunciado y no sobre los hechos, ya que los hechos suceden o no, los hechos son o no son ${ }^{52}$, mientras que los enunciados sí pueden ser verdaderos en cuanto se ajusten a los hechos ${ }^{53}$. En este último sentido, la verdad puede ser considerada como una propiedad del enunciado asertivo ${ }^{54}$, y no de los hechos.

Resulta curioso en este sentido que, no obstante esta bizantina discusión, el mensaje del proyecto de nuevo Código Procesal Civil de Chile, ingresado el año 2012, señale que se faculta al juez para decretar las medidas probatorias destinadas a obtener la verdad de los hechos discutidos ${ }^{5}$, asumiendo la existencia de una verdad en el proceso ${ }^{56}$.

Así, la discusión entre la verdad y la litigación de los abogados en defensa de sus intereses es tan antigua como "la lucha entre el diablo y el agua bendita" 57 ; y cada autor, según sea su postura ideológica en materia procesal, le asignará, o no, un rol a la verdad en el proceso.

3.- El Derecho. Finalmente, el tercer elemento que interviene es el Derecho, el "moderno Derecho impuesto por autoridades, que requiere de una fundamentación en términos de una racionalidad propia, que supone una interpretación obligatoria y que, necesita contar con procedimientos de imposición eficaces" 58 . En una concepción más moderna, se señala que el derecho, además de ser un conjunto de normas jurídicas obligatorias (derecho explícito), está integrado por principios jerárquicamente ordenados que están implícitos, o al menos presu-

transigir válidamente o bien porque recae sobre hecho cuya investigación prohibe la ley. Esta excepción se sustenta en la circunstancia de que el existir una manifestación de la parte contraria podría conllevar dejar de lado la verdad material de los hechos controvertidos para acoger simplemente la formal...".

51 Marinoni y Cruz (2015), p. 75.

52 Carnelutti señalaba que el juez busca la verdad del hecho a probar a través de los medios de prueba, y el hecho no es más que la fuente de la prueba que le permite deducir la propia verdad. CARNELUTTI (2000), pp. 70-71.

53 Maturana (2014), p. 31.

54 TARUfFo (2002), p. 117.

55 Palomo et al. (2015), p. 84.

56 El proyecto presentado en el año 2009 no hacía referencia al tema de la verdad, ni mucho menos establecía su búsqueda como un objetivo del proceso.

57 Calamandrei (1989), pp. 123-125..

58 Habermas (2001), p. 502. 
puestos por el derecho explícito, lo que constituye al Derecho como un todo, un concepto integral ${ }^{59}$ destinado a normar nuestra vida como comunidad civilizada.

Pero no siendo el objeto del presente artículo desarrollar la idea de Derecho, podemos quedarnos con la clásica concepción de que es el conjunto de normas que regulan la conducta humana, con criterios de generalidad, permanencia y abstracción, que tiene la capacidad de hacer cumplir sus disposiciones por medios coercitivos aceptados por la sociedad. El Derecho regula la conducta humana por medio de los criterios de interpretación que tiene acerca de la sociedad y sus fines, lo cual lleva implícito una concepción de sociedad ideal a la cual aspira, por lo que requiere conocer cuál es la verdadera constitución y motivación de la sociedad, que le permita conocer la identidad real de los factores que la constituyen y, con ello, buscar los medios idóneos para lograr el Bien Común, que mira a esa verdad que supone tiene la sociedad.

Por esto, el concepto de verdad toma relevancia, toda vez que si los factores que la constituyen (étnicos, culturales, sociales o de cualquier otra índole) no se acercan a ella, el modelo o sistema jurídico que se construya difícilmente podrá interpretar con fidelidad a la sociedad política, y si ello no es coherente ni coincidente, la crisis institucional es inminente e inevitable, de manera que un Derecho sin verdad no puede solucionar los conflictos de la sociedad política.

Así, el conocimiento de la "verdad" constituye un desafío de difícil solución, pero en el ámbito del 'Derecho' y del 'Proceso' tiene una dimensión mucho más acotada que permite entregar una solución viable, y a la vez necesaria, a la convivencia humana, buscando que el tribunal alcance convicciones acerca de cuál es la verdad. Es viable por cuanto su desarrollo permite obtener respuestas objetivas, como la que entrega una sentencia judicial, que permite dar respuesta a los requerimientos de la sociedad ante un conflicto de relevancia jurídica ${ }^{60}$; y a la vez es necesaria, porque la comunidad jurídica necesita de respuestas objetivas legitimadas para responder a los conflictos que en ella se presentan y que, cuando vienen del órgano jurisdiccional, tienen una connotación muy diversa que cuando vienen de la opinión pública o de órganos gubernamentales, por la objetividad que se le exige al órgano judicial versus la informalidad de la opinión pública y el interés partidista del órgano gubernamental.

59 DwORKIN (1984), pp. 77-78.

60 Evidentemente que la calidad de la misma va a permitir una mayor legitimidad y aceptación de la verdad en la comunidad. 
De este modo, la verdad alcanzada en un proceso llevado conforme a Derecho, constituye una certeza esencial para la convivencia humana, lo que conforma un pilar y base fundamental de una sociedad política. Por ello, la verdad se constituye en un derecho y la sociedad tiene derecho a conocerla cuando ella se ha judicializado.

En el sentido anterior, la existencia de instituciones procesales como la prescripción, la preclusión, el abandono del procedimiento, los sobreseimientos, o incluso las conciliaciones, avenimientos y acuerdos reparatorios, pudieran aparecer como incompatibles con este derecho a la verdad cuando la discusión se ha judicializado, pero ello no es así, porque la certeza y seguridad jurídica son también valores que conviven con la justicia y la sociedad los entiende como válidos para poner término a los conflictos, aun cuando con ellos se renuncia a la verdad, y no admite mayor reparo en el ámbito común.

No obstante lo dicho precedentemente, existen ciertas causas en las cuales, más allá del conflicto jurídico puntual que convoca a la intervención de la justicia, existe un interés superior comprometido que hace inoperable los institutos procesales que terminan con los procesos e investigaciones sin llegar a la verdad judicial, como los señalados precedentemente, en particular las amnistías, autoamnistías ${ }^{61}$ y la prescripción ${ }^{62}$, en aquellos casos que dicen relación con los procesos o causas por crímenes de lesa humanidad o de vulneración flagrante de los derechos fundamentales y de la dignidad de la persona, donde el conocimiento de la verdad es esencial para la reparación de las víctimas y sus familiares, como también para el progreso de los pueblos y la prevención de la reiteración de estos crímenes de lesa humanidad a futuro o en otros lugares ${ }^{63}$.

La construcción y sustentación de toda sociedad política civilizada de convivencia humana exigen que determinadas situaciones sean esclarecidas sin importar el tiempo, lugar ni circunstancias, pues la dignidad humana no tiene límites de tiempo, espacio ni condiciones, lo que hace que este anhelo de conocer la verdad

61 Convención Americana de Derechos Humanos, Comentarios (2014), pp. 637-639.

62 Convención Americana de Derechos Humanos, Comentarios (2014), pp. 640-642.

63 En este sentido no nos queremos quedar sólo son aquellos que son productos de las crisis humanitarias, pues entendiendo que en algunos casos el objeto del crimen afecta mucho más allá de la comisión del ilícito, siendo un atentado de suma gravedad contra la dignidad humana, somos partidarios de extender este criterio a ciertos crímenes comunes, pero que impactan profundamente en las entrañas de una sociedad, como es el caso de un secuestro con violación y asesinato de un menor, por ejemplo, o incluso para situaciones como las matanzas cometidas en colegios en Estados Unidos, y por supuesto para casos como la detención y desaparición de 43 estudiantes en México; no sólo las familias merecen y necesitan saber los detalles, sino toda la comunidad internacional. 
de cuanto aconteció, y que afecta a la dignidad humana, no pueda ser restringido mientras existan dudas sustentables ${ }^{64}$ de lo realmente ocurrido.

En síntesis, podemos señalar que conocer, en el ámbito de las violaciones a los derechos humanos y atentados contra la dignidad de la persona humana, la verdad de lo ocurrido es un imperativo moral, jurídico y esencial de toda víctima, pero además es un imperativo para los victimarios ${ }^{65}$ y para toda sociedad ${ }^{66}$, tanto en el plano local como en el plano internacional, atendida la naturaleza de este ámbito y los efectos de estos atentados contra el ser humano. Ninguna sociedad puede permanecer sana y sin efectos de las heridas causadas por las crisis humanitarias que causan vulneración de derechos fundamentales, si la verdad no se ha buscado y alcanzado en su mayor eficacia, dejando no sólo la incertidumbre de lo ocurrido, sino también un hito histórico sin resolver en el pueblo afectado y una nueva vulneración de la dignidad humana causada por la impunidad que la ausencia de verdad provoca en estas causas. La búsqueda de y el encuentro con la verdad en este campo es tanto necesaria como irrenunciable e imprescriptible.

\section{II. ¿PODEMOS hablar ENTONCES de un Derecho a la Verdad? ¿EN Qué consiste?}

Dentro del catálogo de derechos humanos, el reconocimiento de la verdad como un derecho fundamental es reciente; ella ha surgido en el marco de las investigaciones por crímenes y violaciones a los derechos humanos. En este sentido, nosotros podemos conceptualizarlo como aquel derecho que tiene la víctima de una violación de sus derechos esenciales, que emanan de su

64 Sin querer abrir una puerta indeterminada a la justificación de un límite de este derecho, entendemos que hay una duda sustentable cuando existen aristas no investigadas o no conclusivas que pueden seguir siendo aclaradas, y a contrario sensu entendemos que se puede tener una certeza, aun cuando existen opiniones diversas, cuando éstas no tienen un fundamento plausible o acreditable, como, por ejemplo, cuando se dice que hay un testigo clave que apoya esta tesis diferente y este testigo está fallecido.

65 Sí, estimamos que los victimarios no sólo tienen el derecho a conocer la verdad, sino que también tienen la obligación de conocerla, en sus hechos, en su forma, en su integridad y en sus efectos; es la única manera de hacer justicia en materia de derechos humanos, particularmente cuando en estos temas siempre hay negativas sistemáticas de los victimarios, leyes de amnistía e impunidad, pactos de silencio, amenazas y grupos de facto que siguen operando por algún tiempo, y, sobre todo, propaganda oficialista que desvirtúa la realidad de lo ocurrido, agravando aún más el daño a la dignidad de las víctimas y sus familias. Por lo que el conocimiento y difusión de la verdad es un imperativo de la justicia.

66 Resolución No 65/196 de Naciones Unidas (2015). 
naturaleza humana, como también su familia y la sociedad, a disponer de un recurso efectivo (rápido y sencillo) que le permita conocer la verdad del abuso sufrido o cometido, el reconocimiento público del sufrimiento infringido y las medidas de reparación que sean pertinentes y oportunas al caso; verdad que debe intentar comprender la identificación de los autores, las causas que originaron el abuso, y, en el caso de las desapariciones forzadas y muertes, conocer las circunstancias en que ellas ocurrieron y el destino y ubicación de las víctimas o sus cuerpos.

Se trata, por ende, de un derecho de reciente conceptualización y que tiene especial desarrollo a partir de las violaciones a los derechos humanos cometidas en países de África y Centroamérica hacia los años 60 y 70, extendiéndose hacia los países de América del Sur desde los años 70; situaciones que generaron, desde 1974 a 2007, al menos 32 comisiones en 28 países, incluido Chile, según informa Amnesty International 67.

Este derecho es un derecho que, además, ha evolucionado, como todos los derechos, en virtud del principio de progresividad, evolución que incluso abarca la titularidad del derecho, puesto que en un comienzo sólo se consideraba a las familias (en la mayoría de los casos la víctima estaba desaparecida) y la víctima como titulares de la acción; y la Comisión Interamericana de Derechos Humanos reconoce hoy no sólo a la víctima y a la familia, sino que también reconoce esta titularidad a la sociedad en general ${ }^{68}$.

La jurisprudencia de la Corte IDH ha hecho reiteradas referencias en sus fallos en relación al reconocimiento de este derecho a la verdad, por ejemplo:

- La familia de las víctimas siempre tiene el derecho a conocer el destino de ellas y, cuando corresponda, su ubicación, incluso aunque no se identifique a los victimarios ${ }^{69}$;

67 Amnesty International (2013), "Derecho a la verdad".

68 Por ejemplo, en Sentencia Corte IDH 3/11/1997, Caso Castillo Páez, serie C No 34, párrafo 90. El derecho a la verdad es un derecho de los familiares de los desaparecidos conocer el destino de éstos; en la Sentencia Corte IDH 18/09/2003. Caso Bulacio, serie C No 100, párrafo 114 también se habla de que es un derecho de la víctima o sus familiares saber que ocurrió; pero, a dos meses de ese fallo, viene la Sentencia Corte IDH 25/11/2003. Caso Myrna Mack Chang, serie C No 101, párrafo 274, en el cual expresa que es un derecho de toda persona, incluyendo a los familiares de las víctimas, y luego agrega que es una necesidad que el Estado debe satisfacer a la víctima y a la sociedad; y ya en la Sentencia Corte IDH 22/09/2009 del caso Anzualdo Castro vs. Perú, serie No C 202, párrafos 118 y 119, habla de que respecto del derecho a la verdad, es una expectativa justa que el Estado debe satisfacer y divulgar a la comunidad.

69 Sentencia Corte IDH 3/11/1997, Caso Castillo Páez, serie C No 34, párrafo 90. 
- Toda persona, incluyendo a los familiares de las víctimas, tiene derecho a conocer la verdad en casos de graves violaciones a los derechos humanos, es decir, la familia y la sociedad toda ${ }^{70}$;

- El derecho a la verdad constituye un medio importante de reparación ${ }^{71}$;

- El derecho a la verdad debe ser obtenido de la manera más oportuna posible, el Estado no puede agotar su obligación con posibilitar un debido proceso, debe garantizar que éste se desarrollará en un plazo razonable ${ }^{72}$;

- El derecho a la verdad exige la adopción de los mecanismos más idóneos por parte del Estado para que este derecho sea realidad y permita la determinación procesal de la más completa verdad histórica posible ${ }^{73}$;

- Es un derecho de las víctimas o sus familias conocer el expediente médico para el esclarecimiento de los hechos violatorios ${ }^{74}$, en el cual indirectamente se refiere al derecho a la verdad cuando se alude al derecho al "esclarecimiento de los hechos";

- El derecho a la verdad incluye el derecho a conocer el destino de las víctimas y la ubicación de sus restos; es una obligación de los Estados satisfacer la exigencia de conocer la verdad ${ }^{75}$;

- Los Estados deben realizar de buena fe todas las diligencias necesarias para conocer la verdad de lo ocurrido ${ }^{76}$, especialmente en casos de violaciones a los derechos humanos ${ }^{77}$.

De esta forma, el derecho a la verdad tiene un amplio reconocimiento en la jurisprudencia de la Corte $\mathrm{IDH}^{78}$, donde podemos encontrar conceptos que dicen relación al derecho a conocer el destino y dónde están los restos y el deber,

70 Sentencia Corte IDH 25/11/2003, Caso Myrna Mack Chang, serie C No 101, párrafo 274.

71 Sentencia Corte IDH 27/02/2002, Caso Trujillo Oroza, serie C No 92, párrafo 114.

72 Sentencia Corte IDH 18/09/2003, Caso Bulacio, serie C No 100, párrafo 114.

73 Sentencia Corte IDH 11/05/2007, Caso de la Masacre de la Rochela, serie No C No 163, párrafo 195.

74 Sentencia Corte IDH 22/11/2007, Caso Albán Cornejo y Otros, serie No C 171, párrafo 52.

75 Sentencia Corte IDH 22/09/2009, Caso Anzualdo Castro vs. Perú, serie No C 202, párrafo 118.

76 EsPejo y LeIVA (2012), párrafo 396.

77 Sentencia Corte IDH 31/08/2011, Caso Contreras y Otros vs. El Salvador, serie No C 232, párrafo 170.

78 Otros fallos que lo reconocen son; Sentencia Corte IDH 22/02/2002, Caso Bámaca Velásquez con Guatemala, serie No C 77, párrafo 76; Sentencia Cortte IDH 5/07/2004, Caso 19 Comerciantes, Serie C No 109, párrafo 261; Sentencia Corte IDH 8/07/2004, Caso de los Hermanos Gómez Paquiyauri, Serie C No 110, párrafo 230; Sentencia Corte IDH 15/06/2005, Caso de la Comunidad Moiwana, Serie C No 124, párrafo 204; Sentencia Corte IDH 5/07/2006, caso Vargas Areco, Serie C No 150, párrafo 289; Sentencia 
como obligación positiva del Estado, de alcanzar esa verdad, ya reconocidos desde el caso Velásquez Rodríguez del año 198879; reiterado en el deber del Estado de investigar con seriedad, como deber jurídico y no como una simple gestión, como se establece en el caso Godínez Cruz, en el fallo del año $1989^{80}$.

Por otro lado, la Corte Constitucional de Colombia, conociendo de la acción de inconstitucionalidad en contra del "Marco de Justicia Transicional para el establecimiento de una paz estable y duradera", señaló que dicha norma debía garantizar, entre otros, el derecho a la verdad (el cual, incluso, señala de forma separada al derecho de reparación); que al establecer los criterios de selección y priorización se exija, entre otros, el respeto del derecho la verdad; que la suspensión de la ejecución de las penas, cuando proceda, se haga con miras a satisfacer, entre otros, el derecho a la verdad de las víctimas; que se establezcan comisiones de verdad que ayuden a esclarecer crímenes y violaciones a los derechos humanos ${ }^{81}$. En este sentido, la Ley de Justicia y Paz $^{82}$ establece y reconoce este derecho ${ }^{83}$ y señala que ni siquiera la prioridad política de contribuir a la desmovilización de los grupos armados hace desaparecer la obligación del Estado de buscar la verdad sobre los desaparecidos ${ }^{84}$.

Asimismo, se puede citar la Ley de Memoria Histórica de España ${ }^{85}$, la que si bien no "resucitará a los asesinados, ni devolverá los años robados a los encarce-

Corte IDH 4/07/2007, Caso Zambrano Véliz y otros, Serie C No 166, párrafo 115; Sentencia Corte IDH 3/04/2009, Caso Kawas Fernández versus Honduras, Serie C No 196, párrafo 117, entre otros.

79 “... el derecho de los familiares de la víctima de conocer cuál fue el destino de ésta y, en su caso, dónde se encuentran sus restos, representa una justa expectativa que el Estado debe satisfacer con los medios a su alcance." Sentencia Corte IDH 29/07/1988, Caso Velásquez Rodríguez con Honduras, Serie No C 04, párrafo 181.

80 “... Sin embargo, debe emprenderse con seriedad y no como una simple formalidad condenada de antemano a ser infructuosa. Debe tener un sentido y ser asumida por el Estado como un deber jurídico propio y no como una simple gestión de intereses particulares, que dependa de la iniciativa procesal de la víctima o de sus familiares o de la aportación privada de elementos probatorios, sin que la autoridad pública busque efectivamente la verdad....". Sentencia Corte IDH, 20/01//1989, Caso Godínez Cruz vs. Honduras, serie No C 5, párrafo 188.

81 Sentencia Corte Constitucional Colombia de 28/08/2013, sobre Inconstitucionalidad "Marco de Justicia Transicional para el establecimiento de una paz estable y duradera”, Rol No 579/13, párrafo 7.2.1.

82 Ley No 975/2005, Colombia.

83 "Artículo 4". Derecho a la verdad, la justicia y la reparación y debido proceso. El proceso de reconciliación nacional al que dé lugar la presente ley, deberá promover, en todo caso, el derecho de las víctimas a la verdad, la justicia y la reparación y respetar el derecho al debido proceso y las garantías judiciales de los procesados".

84 González y Varney (2013), p. 10.

85 Ley No 52/2007 de 26/12/2007. 
lados, ni dará una segunda oportunidad a la multitud de vidas que el período de la Guerra Civil y el franquismo truncó, pero, con el reconocimiento del derecho a la verdad de las víctimas, y de sus descendientes haremos justicia como sociedad y contribuiremos a cerrar de forma verdadera las cicatrices..." 86 .

Sin embargo, si bien se ha reconocido la existencia de este derecho a la verdad, también debemos ser claros y señalar que la misma Corte IDH, si bien lo reconoce, lo ha cifrado no como un derecho autónomo, sino como un derecho subsumido dentro de otros derechos; como un derecho de las víctimas o sus familiares al esclarecimiento de los hechos por medio de la investigación ${ }^{87}$, y como parte del derecho de las víctimas o sus familiares al acceso a la justicia y como una forma de reparación ${ }^{88}$, y como un derecho comprendido dentro del derecho a la investigación o derecho a la protección judicial efectiva ${ }^{89}$, lo que nos parece, como ya se ha dicho, insuficiente.

También la Suprema Corte de Justicia mexicana ha reconocido este derecho cuando declara inconstitucional, norma del Código Militar que remite al fuero militar causas penales seguidas contra militares cuando en ellas se puedan afectar los derechos humanos de personas civiles, ya que éstas tienen derecho a ejercer sus acciones y hacer efectivos sus derechos a la verdad y a la justicia, derecho a la verdad que enmarcan dentro del acceso a la justicia ${ }^{90}$.

Además, algunos magistrados de la Corte IDH, en fallos de mayoría, y también en votos particulares, han manifestado que las "autoamnistías violan los derechos a la verdad y a la justicia..."91, con lo cual hacen un expreso reconocimiento a un derecho que invocan, separadamente, y en una misma instancia, respecto del derecho a la justicia.

Por todo esto, no podemos concluir sino que existe este derecho a la verdad, con un reconocimiento expreso, tanto en el orden convencional y doctrinario como también jurisprudencial. Falta entonces la determinación o reconocimiento unánime de este derecho como derecho fundamental autónomo, calificación que,

\footnotetext{
86 Rodríguez (2009), p. 39.

87 Sentencia Corte IDH 28/11/2005, Caso Blanco Romero y Otros, Serie No C 138, párrafo 62.

88 Sentencia Corte IDH 31/01/2006, Caso Masacre de Pueblo Bello, Serie No C 140, párrafo 219.

89 Sentencia Corte IDH 4/09/2012, Caso Comunidad de Rio Negro vs. Guatemala, Serie No C 194, párrafo 250.

90 Sentencia Corte Suprema México, 14/07/2011. Controversia de constitucionalidad sobre artículo 57, fracción II del Código de Justicia Militar, párrafo octavo, No 40.
}

91 Cancado (2013), p. 161. 
desde nuestra perspectiva, creemos que ya tiene, toda vez que para que un derecho fundamental sea autónomo debe tener existencia con independencia de todo otro derecho, lo cual implica una vida propia sin necesidad de uno o más derechos que lo sustenten ni tampoco que se encuentre subsumido dentro de otros derechos.

En este sentido, el derecho a la verdad se valida por sí mismo desde el momento en que existen "comisiones de verdad", las que buscan, justamente, establecer la historia lo más fidedigna posible de un acontecimiento histórico y que van más allá de cualquier proceso judicial, de manera tal que su existencia es independiente tanto del debido proceso en general como del acceso a la justicia, el derecho a la investigación y las garantías de una tutela judicial efectiva en particular.

Es un derecho que va más allá de lo jurisdiccional, pues se trata de un derecho vinculado a la historia y cultura de los pueblos y que, por ende, tiene una connotación que trasciende el crimen cometido, constituyendo un derecho que admite como titular no sólo a la víctima y sus familiares, sino también a la sociedad entera, con la comunidad internacional incluida. Se trata de un derecho inalienable, de aquellos que no admiten suspensión 92 .

\section{III. ¿CUÁL ES EL ORIGEN Y CONTENIDO DE ESTE DERECHO?}

Se discute si este derecho nace como un derecho autónomo o no; de hecho, no surge de ninguna convención, pacto o tratado internacional que lo haya reconocido expresamente como tal. Y frente a este tema hay quienes plantean que este derecho surge como derivación o consecuencia de la aplicación de otros derechos $^{93}$, y hay otros que postulan que es un derecho autónomo, análisis que ya hemos realizado precedentemente y que, en síntesis, podemos señalar que se plantea como parte de la cualidad expansiva de los derechos fundamentales, con un

\footnotetext{
92 Alto Comisionado Naciones Unidas (2009), "Estudio sobre el Derecho a la Verdad", p. 32.

93 La Corte Interamericana de Derechos Humanos ha señalado que no estima que sea un derecho autónomo en el caso Castillo Páez con Perú, donde reconoce, sin embargo, que puede ser un concepto en desarrollo doctrinal y jurisprudencial, pero que en el caso concreto se encontraba ya resuelto en el derecho a la investigación -Convención Americana de Derechos Humanos, Comentarios (2014), p. 633-. Así lo señalan casos como Sentencia Corte IDH, 1/09/2015, Caso Comunidad Campesina Santa Bárbara versus Perú, Serie C No 299, párrafos 261 a 265; y que enmarca el derecho a la verdad dentro del derecho al acceso a la justicia. En cambio, la Sentencia Corte IDH, 14/11/2014, Caso Rodríguez Vera y otros versus Colombia, Serie C No 287, párrafo 509, considera que el derecho a la verdad constituye un derecho contemplado dentro del derecho a la investigación judicial; mientras que en la Sentencia Corte IDH caso Gomes Lund y Otros (Guerrilha de Araguaia) con Brasil, 24/11/2010, serie C 219, párrafos 201 y 211, se enmarca dentro del derecho a buscar y recibir información.
} 
origen a partir de otros derechos, pero que continúa y se reconoce en la actualidad como un derecho autónomo, tanto en su dimensión individual como colectiva ${ }^{94}$.

Hay antecedentes para señalar que es un derecho que se deriva de otros derechos; por ejemplo, puede decirse que es una manifestación del derecho de acceso a la justicia ${ }^{95}$, en cuanto ella, la justicia, exige para ser tal que se funde en la verdad socialmente reconocida por la comunidad; también como un derivado del derecho a las garantías judiciales (juicio justo o debido proceso ${ }^{96}$ ), en cuanto el conocimiento de qué ocurrió es determinante para la sentencia ${ }^{97}$; o como un antecedente que permita justificar el derecho a la reparación ${ }^{98}$, en cuanto para poder reparar el daño, de manera integral, es necesaria la verdad ${ }^{99}$ como elemento esencial en el respeto de la dignidad de la persona humana. También se le considera un derivado de la protección judicial, en cuanto al derecho a un recurso sencillo ${ }^{100}$, que debe conducir al establecimiento de la verdad; o, incluso, como se ha manifestado y reconocido últimamente, como un derivado del derecho a la libertad de pensamiento y de expresión ${ }^{101}$, toda vez que conocer la verdad de hechos que han trascendido a la comunidad y que, generalmente, han sido desvirtuados por los órganos oficiales, es una necesidad imperiosa.

Por otro lado, también se puede decir que es un derecho que surge de manera autónoma ${ }^{102}$, puesto que los elementos que lo constituyen se encuentran bien determinados y no son dependientes de los demás derechos ya comentados, sin perjuicio de que no debe olvidarse que todos los derechos fundamentales conforman una unidad integrada, aplicable a toda persona, por lo que la manifestación

94 Mesía (2004), p. 187.

95 Caso Gomes Lund y otros con Brasil [Sentencia Corte IDH, caso Gomes Lund y otros (Guerrilha de Araguaia) con Brasil. 24/11/2010, serie C 219, párrafos 201 y 211] y Caso González Medina y familiares con República Dominicana (Sentencia Corte IDH, Caso González Medina y familiares versus República Dominicana 27/02/2012, Serie C No 240, párrafos 263, 264, 265 y 266) [CONVENCIÓN AMERICANA DE Derechos Humanos, Comentarios (2014), p. 633].

96 Alto Comisionado Naciones Unidas (2009), "Estudio sobre el Derecho a la Verdad”, p. 31.

97 Alto Comisionado Naciones Unidas (2009), "Estudio sobre el Derecho a la Verdad”, p. 28.

98 Convención Americana de Derechos Humanos, Comentarios (2014), pp. 843-845.

99 Sentencia Corte IDH 25/11/2003, Caso Myrna Mack Chang, serie C No 101, párrafo 274.

100 Alto Comisionado Naciones Unidas (2009), “Estudio sobre el Derecho a la Verdad”, p. 31.

101 Sentencia Corte IDH 24/11/2011, Caso Familia Barrios con Venezuela, número de serie C 237, párrafo 291.

102 Alto Comisionado Naciones Unidas (2009), “Estudio sobre el Derecho a la Verdad”, p. 28. 
de estos derechos, con mayor o menor fuerza de unos y otros, se va dando dentro del plano del bloque de constitucionalidad, de la progresividad y de la fuerza expansiva ${ }^{103}$ de los derechos esenciales de la persona humana.

El origen fáctico de este derecho estuvo en los casos de desapariciones forzadas de personas; esa forma de criminalidad motivó investigaciones cuya comprensión de las mismas permitió desarrollar un aspecto que hoy nos parece básico y esencial, pero que no siempre lo fue, ya que la preocupación que hoy existe al respeto, a protección y garantía de los derechos fundamentales no es antigua, es de reciente data en la historia de la humanidad. Por ende, si el solo reconocimiento de que todos somos iguales en dignidad y derechos es una realidad sólo desde mediados del siglo pasado ${ }^{104}$, el reconocimiento, consolidación y desarrollo de cada uno de los derechos fundamentales es un género nuevo del cual podemos extraer algunos elementos, pero que, evidentemente, pueden ser insuficientes en el futuro.

Los elementos que podemos identificar en este trabajo son:

1.- Se trata de un derecho que tiene relación directa con el acceso a la justicia ${ }^{105}$, en cuanto todo titular de él requiere de un recurso o acción efectiva, es decir, que sea rápido y sencillo, que ponga en movimiento la acción estatal para la investigación de un crimen denunciado y que pueda establecer la veracidad de lo hechos alegados, la identidad de los responsables y su sanción, y las causas que motivaron tales hechos.

2.- El derecho de los afectados (víctima, familia y sociedad) por la vulneración del derecho a la verdad es un derecho imprescriptible, irrenunciable e intransable ${ }^{106}$, toda vez que el saber qué pasó en un crimen de lesa humanidad está amparado por principios y pactos internacionales que declararan la imprescriptibilidad de ello; además, son irrenunciables e intransables porque no son particularmente disponibles; la sociedad y la humanidad completa están afectadas con ellos ${ }^{107}$, de manera tal que ninguna negociación particular puede asegurar la impunidad frente a ellos ${ }^{108}$.

103 Nogueira (1997), pp. 146-147.

104 Nogueira (1997), p. 107.

105 Sentencia Corte IDH 28/11/2005, Caso Blanco Romero y Otros, Serie No C 138, párrafo 62.

106 Sentencia Corte IDH No 4-6. 28/11/2005, Caso Blanco Romero y Otros, Serie No C 138, párrafo 62.

107 Sentencia Corte IDH 25/11/2003, Caso Myrna Mack Chang, serie C No 101, párrafo 274.

108 Sentencia Corte IDH 22/02/2002, Caso Trujillo Oroza, serie C No 92, párrafo 274. 
3.- Se trata de un derecho que debe incluir la exposición y reconocimiento público de los sufrimientos infligidos ${ }^{109}$, es decir, resulta inseparable de la verdad misma el que ella sea reconocida públicamente ${ }^{110}$, generalmente las victimas de desapariciones forzadas, y en general de crímenes contra la humanidad, no sólo sufren la violación de sus derechos esenciales, en lo físico y psíquico, con el acto criminal, también se genera una verdad oficial que justifica o explica los acontecimientos para el resto de la comunidad, y, en esa explicación oficial, la víctima es presentada como victimario, generando una extensión del daño causado, y, a la vez, se genera una vulneración de un derecho esencial de la comunidad, que es el de conocer la verdad, causando con ello la desinformación y el consiguiente aumento del daño a las familias de las víctimas; es decir, se daña a la víctima y se daña a la comunidad.

4.- La sociedad y sus comunidades también tienen derecho a conocer y a exigir la verdad ${ }^{111}$; no es un derecho privativo de la víctima y sus familias, la verdad es necesaria para una sana convivencia social; construir una sociedad sin verdad significa construir sin base sólida; desde concepciones evangélicas ("la verdad os hará libres") hasta concepciones filosóficas, todas reconocen en la verdad un elemento de construcción social imprescindible para la solidez del tejido social que va a servir de fundamento para la construcción de la sociedad política.

5.- La verdad constituye un fundamento esencial para el derecho a la reparación $^{112}$, derecho establecido a favor de la víctima, su familia y la sociedad, toda

109 Sentencia Corte IDH 4/09/2012. Caso Comunidad de Río Negro vs. Guatemala, Serie No C 194, párrafo 250.

110 "194. Por otro lado, este Tribunal también ha señalado que en una sociedad democrática se debe conocer la verdad sobre los hechos de graves violaciones de derechos humanos. Esta es una justa expectativa que el Estado debe satisfacer, por un lado, mediante la obligación de investigar de oficio las graves violaciones de derechos humanos y, por el otro, con la divulgación pública de los resultados de los procesos penales e investigativos. Esto exige del Estado la determinación procesal de los patrones de actuación conjunta y de todas las personas que de diversas formas participaron en dichas violaciones y sus correspondientes responsabilidades y reparar a las víctimas del caso. Por ello, en ocasiones anteriores la Corte ha considerado que las autoridades encargadas de las investigaciones tienen el deber de asegurar que en el curso de las mismas se valoren los patrones sistemáticos que permitieron la comisión de graves violaciones de los derechos humanos, como los sucedidos en el presente caso. En aras de garantizar su efectividad, la investigación debe ser conducida tomando en cuenta la complejidad de este tipo de hechos y de la estructura en la cual se ubican las personas probablemente involucradas en los mismos, de acuerdo al contexto en que ocurrieron, evitando asi omisiones en la recaudación de prueba y en el seguimiento de líneas lógicas de investigación. Por ello, las autoridades estatales están obligadas a colaborar en la recaudación de la prueba para alcanzar los objetivos de una investigación y abstenerse de realizar actos que impliquen obstrucciones para la marcha del proceso investigativo". Sentencia Corte IDH 4/09/2012, Caso Comunidad de Río Negro vs. Guatemala, Serie No C 250, párrafo 194.

111 Sentencia Corte IDH 24/11/2010, Caso Gomes Lund y Otros (Guerrilla de Araguaia), serie C No 219, párrafos 201 y 211.

112 Convención Americana de Derechos Humanos, Comentarios (2014), p. 634. 
vez que el derecho a la reparación comprende una reparación integral, moral, indemnizatoria y social ${ }^{113}$. Esto implica que a partir de la verdad puede venir el duelo, la conmemoración de la vida de las víctimas, en las diversas formas que la cultura, dignidad y el sentir de la comunidad lo requiera.

6.- El derecho a la verdad excluye las amnistías y plazos de prescripción en los crímenes de lesa humanidad ${ }^{114}$, toda vez que la amnistía significa olvido y, como consecuencia de ello, la ignorancia de lo que sucedió, pilar central de la verdad. La prescripción, como criterio de certeza, queda excluida en el ámbito de las violaciones a los derechos humanos, constituye una excepción a la búsqueda de la seguridad jurídica, toda vez que se trata de aquellos hechos que trascienden la contingencia y contemporaneidad del momento en que ocurren; la humanidad no deja de vivenciarlos, a diferencia de los crímenes y delitos comunes, en que el tiempo no sólo permite olvidar su comisión, también la sociedad lo hace y no trascienden en la historia ${ }^{115}$. Así, un fundamento básico de la imprescriptibilidad de los delitos de lesa humanidad es la superposición de la verdad por sobre la ignorancia y el olvido; el ser humano vale más que la norma, y, por ello, la justicia vale más que la seguridad jurídica, que, en este caso concreto, significa o trae como consecuencia, la impunidad.

7.- Así, además, el derecho a la verdad impone al Estado obligaciones concretas:

i.- Buscarla y agotar los medios para ello ${ }^{116}$;

ii.- Reconocerla, hacerla pública ${ }^{117}$;

iii.- Realizar los actos reparatorios que sean necesarios a favor de las víctimas, familias y la sociedad misma118;

iv.- Realizar los actos legislativos, y de cualquier otra naturaleza, que sean necesarios para evitar la reiteración de los hechos acaecidos, implementando las medidas necesarias de protección y garantía ${ }^{119}$;

\footnotetext{
113 Rousset (2011), pp. 64-72.

114 Convención Americana de Derechos Humanos, Comentarios (2014), pp. 636-642.

115 Bernales (2014), pp. 156-157.

116 Sentencia Corte IDH 29/07/1988. Caso Velásquez Rodríguez con Honduras, Serie No C 04, párrafo 181.

117 Sentencia Corte IDH 4/09/2012. Caso Comunidad de Río Negro vs. Guatemala, Serie No C 194, párrafo 250.

118 Sentencia Corte IDH No 9-15. 28/11/2005, Caso Blanco Romero y Otros, Serie No C 138, párrafo 62.

119 Sentencia Corte IDH 11/05/ 2007, Caso de la Masacre de la Rochela, serie No C No 163, párrafos 193,194 y 195.
} 
v.- Conservar todos los antecedentes y la evidencia de todo tipo sobre los hechos aclarados, como asimismo garantizar el acceso a los mismos a toda persona y la difusión educativa de ellos como forma de hacer tomar conciencia a la sociedad ${ }^{120}$.

8.- Su búsqueda puede ser por la vía judicial o por vía no judicial; así, no sólo los tribunales de justicia, nacionales o internacionales, velan por la búsqueda de ella, también hay instancias no judiciales, como las comisiones de verdad que se han creado en diversos Estados que han tenido problemas de vulneración de derechos humanos ${ }^{121}$.

9.- Tan importante como la verdad de lo ocurrido es el conocer las causas de por qué ocurrió; es la forma que tiene la sociedad de prevenir una repetición de ello, saber por qué pasó lo que pasó, entender las causas del abuso ${ }^{122}$.

10.- El derecho a la verdad va de la mano con el derecho a la justicia; el problema se presenta con la seguridad jurídica, donde, en temas de delitos comunes, ella puede imponerse al valor de la justicia, por cuanto no puede prolongarse un proceso de forma indefinida, ya que dicha indefinición daña más a la justicia que el propio delito, por lo que la certeza jurídica permite alcanzar un mayor grado de justicia. Sin embargo, esto no es posible aplicarlo en crímenes de lesa humanidad, toda vez que ahí la víctima no sólo es el desaparecido y su familia, es la sociedad completa, y por ello, en tales crímenes, sólo la verdad permite alcanzar una justicia real.

120 Sentencia Corte IDH 22/02/2002, Caso Bámaca Velásquez con Guatemala, serie No C 77, párrafo 76.

121 Sentencia Corte IDH 4/07/2007, Caso Zambrano Véliz y Otros, Serie C No 166, párrafo 128: "La Corte estima que el establecimiento de una comisión de la verdad, según el objeto, procedimiento, estructura y fin de su mandato, puede contribuir a la construcción y preservación de la memoria histórica, el esclarecimiento de hechos y la determinación de responsabilidades institucionales, sociales y politicas en determinados periodos históricos de una sociedad. Las verdades históricas que a través de ese mecanismo se logren, no deben ser entendidas como un sustituto del deber del Estado de asegurar la determinación judicial de responsabilidades individuales o estatales por los medios jurisdiccionales correspondientes, ni con la determinación de responsabilidad internacional que corresponda a este Tribunal. Se trata de determinaciones de la verdad que son complementarias entre sí, pues tienen todas un sentido y alcance propios, así como potencialidades y límites particulares, que dependen del contexto en el que surgen y de los casos y circunstancias concretas que analicen. En efecto, la Corte ha otorgado especial valor a los informes de Comisiones de la Verdad o de Esclarecimiento Histórico como pruebas relevantes en la determinación de los hechos y de la responsabilidad internacional de los Estados en diversos casos que han sido sometidos a su jurisdicción".

122 Sentencia Corte IDH 22/02/2002, Caso Bámaca Velásquez con Guatemala, serie C No 91, párrafo 77. 


\section{IV. ¿CUÁl ES EL RECONOCIMIENTO NORMATIVO \\ de este derecho para el Estado de Chile?}

En el nuestro caso, la principal fuente de reconocimiento se encuentra en el sistema interamericano, que se fundamenta en el Pacto de San José de Costa Rica, es decir, en la Convención Americana sobre Derechos Humanos; como también en nuestra Carta Fundamental y la Comisión sobre Verdad y Reconciliación.

1.- Convención Americana sobre Derechos Humanos. Aquí no cabe duda que encontramos manifestaciones de este derecho al invocar el artículo $1^{\text {10123 }}$, que establece la obligación de los Estados de respetar todos los derechos y libertades a todo ser humano; luego el artículo $8^{\circ}$, que se refiere a las garantías judiciales, implica necesariamente una construcción de los procesos sobre la verdad en el plano judicial; una sentencia fundada en la mentira o en la ignorancia atenta contra la dignidad humana. El artículo 25, referido a la protección judicial, implica a la vez la posibilidad de acceder a la justicia, es decir, al recurso rápido y sencillo para recuperar o reconocer un derecho afectado, lo que implica conocer y reconocer la verdad como un fundamento de ello ${ }^{124}$.

Finalmente, la jurisprudencia internacional ha ido recogiendo e incorporando como norma relevante en la fundamentación de este derecho el artículo 13 de la Convención sobre la libertad de pensamiento y expresión, que comprende el derecho a buscar, recibir y difundir informaciones de toda índole ${ }^{125}$; en este sentido, esta interpretación, es más reciente. La primera ocasión en que la Comisión IDH consideró este artículo fue en el de un grupo de casos de Chile

123 "Artículo 1. Obligación de Respetar los Derechos

1. Los Estados Partes en esta Convención se comprometen a respetar los derechos y libertades reconocidos en ella y a garantizar su libre y pleno ejercicio a toda persona que esté sujeta a su jurisdicción, sin discriminación alguna por motivos de raza, color, sexo, idioma, religión, opiniones politicas o de cualquier otra indole, origen nacional o social, posición económica, nacimiento o cualquier otra condición social.

2. Para los efectos de esta Convención, persona es todo ser humano".

\section{4 "Artículo 25. Protección Judicial}

1. Toda persona tiene derecho a un recurso sencillo y rápido o a cualquier otro recurso efectivo ante los jueces o tribunales competentes, que la ampare contra actos que violen sus derechos fundamentales reconocidos por la Constitución, la ley o la presente Convención, aun cuando tal violación sea cometida por personas que actúen en ejercicio de sus funciones oficiales...".

125 Sentencia Corte IDH 24/11/2010, Caso Gomes Lund y Otros (Guerrilla de Araguaia), serie C No 219, párrafos 201 y 211. 
denunciados en $1998^{126}$, alegando que la aplicación de la ley de amnistía impedía la investigación de los casos judiciales de desapariciones forzadas de sus familiares, negando con ello, entre otras normas de la Convención, este derecho. Luego se repitió en 1999, con el caso de unos agricultores de El Salvador ${ }^{127}$, que fueron detenidos, torturados y dos de ellos fallecieron; vino una comisión de la verdad que estableció recomendaciones en 1992 y en 1993 una ley de amnistía anuló las recomendaciones de esta comisión de la verdad. En ambos casos, la comisión de la verdad constató las vulneraciones a los derechos y se invocó además este artículo 13, norma que se volvería a repetir en el caso del asesinato de monseñor Óscar Romero de El Salvador, planteado en el año 2000128; en el caso de la desaparición del guerrillero guatemalteco Efraín Bámaca Velásquez ${ }^{129}$, y en el caso Barios Altos de Perú130.

2.- En relación a la Carta Fundamental. En la Constitución chilena podemos encontrar el derecho a la verdad sólo de forma indirecta o tangencial en las siguientes disposiciones: Artículo 19 No 3, el racional y justo procedimiento implica un reconocimiento de este derecho, sin perjuicio de la incorporación hecha por la vía del inciso $2^{\circ}$ del artículo $5^{\circ}$ de la Constitución ${ }^{131}$ y por el bloque constitucional de derechos que permite integrar tanto los derechos de fuentes externas como internas, normas de la misma fuerza normativa constitucional ${ }^{132}$, lo que necesariamente trae como consecuencia la integración de todos los derechos humanos en la aplicación e interpretación de una norma. En definitiva, es el derecho internacional de los derechos humanos y el derecho humanitario el que va a primar al momento de

126 OEA (2011), Relatoría Especial para la Libertad de Expresión, "El Derecho a la Verdad”. Documento electrónico.

127 OEA (2011), Relatoría Especial para la Libertad de Expresión, "El Derecho a la Verdad". Documento electrónico.

128 OEA, Comisión Interamericana de Derechos Humanos, Informe № 37/00 de 13/04/2000, párrafos $152-151,158$ y 161.

129 OEA (2011). Relatoría Especial para la Libertad de Expresión, "El Derecho a la Verdad". Documento electrónico.

130 Sentencia Corte IDH, 14/03/2001, Caso Zambrano Véliz y Otros contra Ecuador, serie C No 166, párrafo 115.

131 Constitución Chile 1980, arts. 5º y 19 No 3.

132 Nogueira (1997), p. 86. 
resolver las cuestiones de vulneración de los derechos fundamentales establecidos como estándar mínimo, conforme al principio favor persona ${ }^{133}$.

3.- Las comisiones sobre verdad han sido un elemento importante, entre otros, para la reconstrucción de la verdad alterada por las propagandas oficialistas que buscan ocultarla en casos graves de violaciones a los derechos humanos; ellas no sólo han ayudado a recuperar la verdad, esclareciendo los hechos, sino que han aportado con pruebas concretas a ayudar a las propias investigaciones judiciales. Ellas representan verdaderos ejemplos de superación de conflictos y han servido en algunos casos para "enfrentar situaciones coyunturales cuya importancia social ha meritado generar una reflexión...” (como en Ecuador y Bolivia) ${ }^{134}$. También ellas han aportado recomendaciones, estudios e investigaciones que permiten, tanto al ejecutivo como al legislativo, adoptar las medidas necesarias para proporcionar reparación para las víctimas y sus familiares, reparación que debe ser integral ${ }^{135}$; instancias de reencuentro de la comunidad quebrantada, y, sobre todo, orientaciones para la búsqueda de caminos de reconciliación y unión, sin renunciar a la verdad ni facilitar la impunidad, constituyen una garantía ${ }^{136}$ para el derecho a la verdad. Estas comisiones son una vía alternativa a la judicial ${ }^{137}$, que la complementan ${ }^{138}$ cuando muchas veces la vía judicial no puede asumir este rol por causas como:

i.- Imposibilidad de que el Estado asuma procesos sin generar violencia social;

ii.- A veces los casos se limitan a los emblemáticos y a las figuras más famosas, lo que reduce la verdad a meros titulares sin contenido;

iii.- Los juicios a veces generan una doble victimización, al exponer a las víctimas nuevamente, por ejemplo, a enfrentar a sus torturadores, a recordar lo que han querido olvidar, a la exposición pública, etc.

Recordemos que en América Latina tenemos desde la Comisión Nacional de Investigación de Desaparecidos Forzados en Bolivia (1982) hasta la Comisión Nacional de la Verdad en Brasil (2012). Y, entre ellas, la Comisión Nacional sobre la Desaparición de Personas en Argentina (1983), la Comisión Nacional de Verdad y Reconciliación en Chile (1990), la Comisión de la Verdad en El Salvador (1992),

133 Nogueira (2003), p. 383.

134 Fajardo (2012), p. 16.

135 Ávila (2012), documento electrónico.

136 Alto Comisionado Naciones Unidas (2009), “Estudios sobre el Derecho a la Verdad”, p. 32.

137 González y VARney (2013), p. 7.

138 Naciones Unidas (2008) Resolución No 9/11, No 2. 
la Comisión Nacional de Verdad y de Justicia en Haití (1995), la Comisión para el Esclarecimiento Histórico en Guatemala (1997), la Comisión para la Paz en Uruguay (2000), la Comisión de la Verdad y la Reconciliación en Perú (2000), la Comisión de la Verdad en Panamá (2001), la Comisión de Verdad y Justicia en Paraguay (2003), la Comisión Nacional de Reparación y Reconciliación en Colombia (2005), la Comisión de la Verdad en Ecuador (2007) y la Comisión de la Verdad y la Reconciliación en Honduras (2009); es decir, catorce comisiones para el esclarecimiento de la verdad ${ }^{139}$. Hasta junio de 2012 había en total 34 comisiones sobre verdad en el mundo ${ }^{140}$.

4.- Otras fuentes:

La Asamblea General de las Naciones Unidas (cuyas declaraciones no son vinculantes) ha reconocido a las víctimas, su familia y la sociedad el derecho a conocer la verdad hasta donde sea posible ${ }^{141-142}$. Tampoco debe dejar de señalarse que los Convenios de Ginebra, Protocolo Adicional de 1977, se refieren expresamente en sus normas a la identificación de heridos y muertos, y la búsqueda de desaparecidos ${ }^{143}$, a facilitar su ubicación y conocer el destino por parte de sus familiares ${ }^{144}$. Lo mismo ocurre con la Convención Internacional para la protección de todas las personas contra las desapariciones forzadas, que plantea en su artículo 12 el derecho a denuncia y a que se haga una investigación exhaustiva (para saber qué pasó); el artículo 22 obliga al Estado a evitar y sancionar la negativa de información y la información inexacta respecto del desaparecido ${ }^{145}$, entre otros documentos internacionales.

También hay fallos de tribunales supremos, como el de la Corte Suprema argentina con el caso "Simón"146; o los de las Cortes Constitucionales de Colombia ${ }^{147}$, el

139 Clavero (2014), documento electrónico.

140 FAJARDO (2012), p. 16.

141 Documento Oficial de la Asamblea General, quincuagésimo primer período de sesiones, Suplemento No 40 (A/51/40), Citado por Comisión Colombiana Juristas (2012), pp. 98-99.

142 NaCiONES UnidAs. Res. No 9/11 de 24/09/2008.

143 Artículos 32 y 33.

144 Protocolo adicional a los Convenios de Ginebra, artículos 33 y 34.

145 Convención internacional para la protección de todas las personas contra las desapariciones forzadas. Artículos 12 y 22.

146 Sentencia Corte Suprema argentina (14/6/2005). Caso Simón, Julio Héctor y otros por privación ilegítima de libertad, Causa No 17.768-2005, considerandos 19), 20), y 21).

147 "Ley de Justicia y Paz", la Corte Constitucional señaló que ni siquiera la posibilidad de desmovilizar a los grupos armados era argumento para que el Estado renunciara a conocer la verdad sobre los desaparecidos. 
Tribunal Constitucional de Perú ${ }^{148-149}$ y la Corte Constitucional de Sudáfrica ${ }^{150-151}$ entre otras.

Finalmente, leyes especiales, como la Ley de Memoria Histórica, a través de la cual el Estado español garantiza el derecho a la verdad de las víctimas de la Guerra Civil ${ }^{152}$, por ejemplo.

\section{CONClusiones}

El tema del derecho a la verdad, que afecta principalmente a las víctimas de las violaciones a los derechos humanos cometidas bajo regímenes autoritarios, guerras u otra causa, es un tema que se fundamenta en el respeto de la dignidad de la persona humana que no sólo ha sufrido la vejación y vulneración de su dignidad, sino que, además, por el transcurso del tiempo, la distorsión de los hechos producida por la propaganda oficialista, la falta de justicia oportuna y la paulatina desaparición de los actores, se ha generado un ambiente de impunidad cuyo efecto principal es una nueva vulneración de la dignidad de la víctima, para quien una reparación eficaz del daño causado parte por el reconocimiento de la verdad de los hechos acaecidos. Se trata, entonces, de un derecho en desarrollo, reconocido por muchos, pero cuyo reconocimiento no alcanza para considerarlo formalmente como un derecho fundamental autónomo, lo que constituye un elemento esencial para una garantía eficaz del respeto íntegro de la dignidad del ser humano.

La verdad es un concepto complejo, el cual difícilmente puede describirse de manera objetiva frente a un hecho que acontece, ya que depende tanto de factores intrínsecos, como el grado educacional y los valores con que se interpreta el hecho, como también de factores extrínsecos, dados, por ejemplo, por la ubica-

Sentencia Corte Constitucional de Colombia 28/08/2013, Rol No 579/13, motivaciones 8.4.2; 8.4.3; 8.4.6; y conclusiones 9.9.1; y 9.9.9.

148 Caso Villegas Namuche, Sentencia Tibunal Constitucional de Perú 18/03/2004, Exp. No 2488-2002 HC-TC, párrafos 13, 14, 15 y 17. En este fallo el Tribunal Constitucional reconoció que el derecho a la verdad es un derecho fundamental reconocido en la Constitución del Perú.

149 Ávila (2012), documento electrónico.

150 En el Caso Mc Bride, la Corte Constitucional reconoció el derecho de las víctimas, de los medios y del público a decir la verdad, aun incluso si los crímenes fueron objeto de amnistía (Sentencia Tribunal Constitucional de Sudáfrica 8/04/2011. The Citizen 1978 (Pty) Ltd and others v. McBride. Case CCT 23/10, 2011, ZACC 11).

151 González y Varney (2013), p. 10.

152 Rodríguez (2009), p. 39. 
ción y sentidos utilizados en la percepción del hecho del cual se requiere relatar la verdad; por ello se trata de la búsqueda de una verdad concreta, la verdad de un acontecimiento.

El proceso nos permite conocer la verdad judicial, es decir, la verdad probada por las partes en un proceso, la que muchas veces se refleja en una sentencia de manera parcializada según lo que cada parte haya podido probar, pero que, por ser la sentencia el producto del proceso, y lo que las partes aportaron a él, es una verdad judicial o procesal, que va más allá de lo que las partes individualmente alegaron y que podrían o no coincidir con la verdad objetiva de lo acontecido. Por su parte, el Derecho es el medio que permite ordenar la convivencia de la sociedad política, y, para que esa convivencia sea armónica, debe reconocer los factores reales o verdaderos de interés social, de manera que dicha regulación se constituya de conformidad a la o las verdades a las que adhiere la sociedad.

En este camino, los conflictos jurídicos deben resolverse con prontitud y eficacia, reconociendo que no todo tiene una solución que se ajuste a una verdad histórica objetiva y única, permitiendo que ciertas instituciones procesales, como los sobreseimientos, acuerdos reparatorios, avenimientos y conciliaciones, y que determinados institutos legales, como la amnistía y la prescripción, impidan la obtención de la verdad. Sin embargo, estos institutos procesales y legales, aunque impiden llegar a la verdad, no afectan y, al contrario, ayudan a la paz social, porque forman parte de la regulación interna aceptada por la sociedad para el logro del bien común, por tratarse de afectaciones de derechos individuales o particulares. Sin embargo, hay ciertos temas en los cuales ya no son intereses particulares los afectados, sino la sociedad toda, y donde el derecho a la verdad surge como un imperativo moral categórico, y ello ocurre en las violaciones a los derechos humanos, cualquiera sea su causa; allí, la verdad está por sobre cualquier instituto alternativo, sea legal o procesal, porque la falta de verdad o, mejor dicho, el no respeto del derecho a la verdad, constituye, en sí una nueva y flagrante vulneración de los derechos fundamentales de las personas, por atentar directamente contra la dignidad del ser humano y, por ende, por atentar contra el principal valor que es intransable en toda sociedad civilizada: la dignidad humana.

El derecho a la verdad, así, tiene una existencia, en nuestro entender, autónoma, puesto que se sustenta a sí mismo, y donde, no obstante su falta de reconocimiento unánime en la actualidad, tiene importante, manifestaciones a nivel jurisprudencial y doctrinario, e incluso formal, como en la Resolución No 9/11 de las Naciones Unidas, en las cuales se lo reconoce formalmente.

Se trata entonces de un derecho en evolución permanente, que reconoce como titulares a la víctima, su familia y la sociedad entera, por lo que se reconoce 
una doble dimensión, de derecho particular y derecho colectivo; es un derecho que obliga al Estado a efectuar las acciones necesarias para alcanzarla; le impide obstaculizar su obtención, ya sea por vías directas como indirectas; obliga al Estado a una actitud positiva para eliminar cualquier barrera legal que dificulte su obtención, constituyendo, de este modo, una garantía en la prevención futura de nuevos abusos. De esta forma, podemos señalar que es parte idónea y esencial dentro de los procesos de reparación para los afectados.

Se trata de un derecho fundamental que, como la mayoría de ellos, comienza su evolución progresiva de manera importante después de la Segunda Guerra Mundial, pero que en particular tiene sus primeras manifestaciones concretas a finales de los años sesenta y comienzo de los años setenta. Se trata de un derecho que se encuentra vinculado al acceso a la justicia, que le permite buscar la verdad por medios jurisdiccionales, que reconoce a la víctima, la familia y la sociedad la titularidad de la acción; es un derecho fundamental que exige un reconocimiento público de los hechos, como parte del proceso de reparación, que siempre debe tener su base en la verdad. La comunidad también tiene derecho a exigir la verdad, y por ello se excluye en esta materia la prescripción y la amnistía como método para lograr la paz social; por ella son válidas no sólo las vías idóneas (jurisdiccionales), sino que también se admiten y valoran las no jurisdiccionales, como las comisiones de la verdad.

Finalmente, Chile tiene un reconocimiento indirecto de este derecho: a través del artículo 19 No 3, en relación al racional y justo procedimiento, el artículo $5^{\circ}$ inciso $2^{\circ}$ con la incorporación de los derechos asegurados por tratados internacionales que los reconocen; también a través de la jurisprudencia y resoluciones de los órganos internacionales, y, por último, un reconocimiento a través del bloque constitucional de derechos, que nos vincula a su respeto, protección y garantía.

\section{Bibliografía}

Bailón, Rosalío (2004). Teoría general del proceso y Derecho Procesal Civil. Preguntas $y$ respuestas. (México, Editorial Limusa SA).

Bentham, Jeremías (1847). Tratado de las pruebas judiciales. (Madrid, Establecimiento Tipográfico de don Ramón Rodríguez de Rivera, Editor).

Bernales, Gerardo (2014). "La imprescriptibilidad de la acción penal en procesos por violaciones a los derechos humanos". (Santiago, artículo publicado en Revista Ius et Praxis, Edición Conmemorativa XX Aniversario. AbeledoPerrotLegalPublishing). 
Bonnier, Eduardo (1869). "Tratado teórico-práctico de las pruebas en Derecho civil y penal". (Madrid, publicado en Revista de Legislación, vol. I).

Bordalí, Andrés (2009). "El Derecho fundamental a un tribunal independiente e imparcial en el ordenamiento jurídico chileno". (Valparaíso, artículo publicado en la Revista de Derecho de la Pontificia Universidad Católica de Valparaiso).

Calamandrei, Piero (1989). Elogio de los jueces escrito por un abogado. (Buenos Aires, Ediciones Jurídicas Europa América).

CANCADo, Antonio (2013). El principio básico de igualdad y no discriminación: construcción jurisprudencial. (Santiago, Editorial Librotecnia).

Carnelutti, Francesco (1947). La prova civile. (Roma, Edizioni dell' Ateneo, 2a Edición).

Carnelutti, Francesco (2000). La prueba civil. (Buenos Aires, Ediciones De Palma).

Cavalloneres, Bruno; Taruffo, Michelle (2012). Verifobia. Un diálogo sobre prueba y verdad. (Lima, Palestra Editores).

Chiovenda, Giuseppe (2001). Serie clásicos del Derecho Procesal Civil. Instituciones de Derecho Procesal Civil. (México, Editorial Jurídica Universitaria).

Coloma, Rodrigo; AgüEro, Claudio (2014). "Lógica, ciencia y experiencia en la valoración de la prueba”. (Santiago, artículo publicado en Revista Chilena de Derecho, vol. 41 No 2).

Comisión Colombiana Juristas (2012). "Derecho a la Verdad y Derecho Internacional”. (Bogotá, Opciones Gráficas Editores).

Constitución Política del Estado de Chile (1980).

Convención Americana de Derechos Humanos, Comentarios (2014). Obra colectiva (Santiago, Steiner y Uribe Editores).

Couture, Eduardo (1998). Estudios de Derecho Procesal Civil. (Buenos Aires, Editorial De Palma, Tomo I).

Damaska, Mirjan (2000). Las caras de la justicia y el poder del Estado. Análisis comparado del proceso legal. (Santiago, Editorial Jurídica de Chile).

Devis, Hernando (2012). Compendio de Derecho Procesal. Pruebas judiciales. (Colombia, Editorial Temis).

Dworkin, Ronald (1984). Los derechos en Serio. Traducción de M. Guastavino. (Barcelona, Editorial Ariel).

Espejo, Nicolás; LeIVA, Carla (2012). Digesto de jurisprudencia de la Corte Interamericana de Derechos Humanos. (Chile, LegalPublishing). 
FAJARDO, Luis (2012). "Elementos estructurales del Derecho a la Verdad". (Colombia, artículo publicado en la Revista Civilizar, Ciencias Sociales y Humanas, Vol. 12 No 22, Editorial Universidad Sergio Arboleda).

Ferrajoli, Luigi (1995). Derecho y razón. (Madrid, Editorial Trotta S.A.).

Ferrer, Jordi (2005). Prueba y verdad en el Derecho. (Barcelona, Marcial Pons, Ediciones Jurídicas y Sociales S.A.).

García, Sergio (2012). El debido proceso. (México, Editorial Porrúa).

GASCÓN, Marina (2004). Los hechos el Derecho: Bases argumentales de la prueba. (Madrid, Editorial Marcial Pons).

GonzÁlez, Eduardo; Varney, Howard (2013). En busca de la Verdad. Elementos para la creación de una comisión de la verdad eficaz". (Brasil, Publicado por Comisión de Amnistía del Ministerio de Justicia de Brasil).

Marinoni, Luiz; CruZ, Sergio (2015). La prueba. (Chile, Editorial Thomson Reuters.

Habermas, Jurgen (2001). Facticidad y validez. (Madrid, Editorial Trota).

Hunter, Iván (2015). La aplicación judicial del Derecho en el proceso civil. (Santiago, Editorial Thomson Reuters).

Kelsen, Hans (2003). La pazpor medio del Derecho. (Madrid, Editorial Trotta S.A.).

Mesía, Carlos (2004). Derechos de la Persona. Dogmática Constitucional. (Lima, Fondo Editorial del Congreso de Perú).

Maturana, Javier (2014). Sana crítica. Un sistema de valoración racional de la prueba. (Santiago, Editorial Thomson Reuters).

Montero Aroca, Juan (2007). La prueba en el proceso civil (España, Editado por Thomson Civitas, Cizur Menor).

Montero ArocA, Juan (2013). "Las concepciones garantista y autoritarias del proceso civil en el siglo XXI”. (Santiago, artículo publicado en Revista del Instituto Panamericano de Derecho Procesal).

Naciones Unidas (1977). "Protocolo Adicional a los Convenios de Ginebra de 1949 relativo a la protección de víctimas de los conflictos armados internacionales". (Santiago, Publicado en Tratados internacionales vigentes en Chile en materia de Derechos Humanos, Editorial del Diario Oficial).

Nogueira, Humberto (1997). Dogmática constitucional. (Talca, Editorial Universidad de Talca).

Nogueira, Humberto (2003). Teoría y dogmática de los derechos fundamentales. (México, Editorial Universidad Nacional Autónoma de México). 
Palomo, Diego; Bernales, Gerardo; Delgado, Jordi et al. (2015). Reforma a la justicia civil. Una mirada desde la judicatura. (Santiago, Ediciones Jurídicas de Santiago).

Rawls, John (1995). La teoría de la justicia. (México, Editado por Fondo de Cultura Económica).

Rodríguez, Antonio (2009). "Reflexiones el derecho a la verdad y la Ley de Memoria Histórica”. (Fecha de consulta: 23 de septiembre de 2015). (Disponible en http://www.mecd.gob.es/cultura-mecd/dms/mecd/cultura-mecd/areascultura/patrimonio/mc/patrimonioculturale/n-1/capitulos/07_PCE1_Reflexiones_Dercecho_verdad.pdf).

Rocco, Ugo (2001). Serie clásicos del Derecho Procesal Civil. Derecho Procesal Civil. (México, Editorial Jurídica Universitaria).

RoussET, Andrés (2011). "El concepto de reparación integral en la jurisprudencia de la Corte Interamericana de Derechos Humanos". (Fecha de consulta: 29 de septiembre de 2015). (Disponible en http://www.corteidh.or.cr/tablas/ usuario/frank/30948.pdf).

Salmón, Elizabeth; BlanCo, Cristina (2012). El derecho al debido proceso en la jurisprudencia en la Corte Interamericana de Derechos Humanos. (Lima, Impreso por Instituto de Democracia y Derechos Humanos de la PUC del Perú y Agencia de Cooperación Alemana al Desarrollo, Agencia ZIG en Perú).

TARUfFo, Michele (2009). La prueba. Artículos y conferencias. (Chile, Editorial Metropolitana).

TARuffo, Michele (2002). La prueba de los hechos (Madrid, Editorial Trotta).

Tribunal Constitucional de Chile (2015). Jurisprudencia comparada. Volumen I. (Santiago, Editado por Tribunal Constitucional).

VAlLEsPín, David (2002). El modelo constitucional de juicio justo en el ámbito del proceso civil (Barcelona, Editorial Atelier).

WilenMAnN, Javier (2014). "El concepto de falsedad en el falso testimonio. Una introducción a la dogmática general de los delitos de falsedad".(Fecha de consulta: 25 de julio de 2015). (Disponible en http://www.scielo.cl/scielo. php?pid=S0718-34372014000100004\&script=sci_arttext).

\section{OTRAS FUENTES}

Alto Comisionado de Las Naciones Unidas (2009). "Estudio sobre el Derecho a la Verdad". (Fecha de consulta: 23 de septiembre de 2015). (Disponible en http://www.mecd.gob.es/cultura-mecd/dms/mecd/cultura-mecd/areas- 
cultura/patrimonio/mc/patrimonioculturale/n-1/capitulos/06_PCE1_Derecho_verdad.pdf).

Amnesty International (2013). "Derecho a la Verdad". (Fecha de consulta: 24 de julio de 2015). (Disponible en https://www.es.amnesty.org/temas/justiciainternacional/hacer-realidad-la-justicia-internacional).

Ávila, Jhonathan (2012). "El Derecho a la Verdad en la Jurisprudencia Constitucional: A propósito del caso Villegas Namuche”. (Fecha de consulta: 4 de septiembre de 2015). (Disponible en https://paradigmasconstitucionales. wordpress.com/2012/11/02/el-derecho-a-la-verdad-en-la-jurisprudenciaconstitucional-a-proposito-del-caso-villegas-namuche/).

Clavero, Bartolomé (2014). "Comisiones de la Verdad en América y no en España”. (Fecha de consulta: 20 de septiembre de 2015). (Disponible en http://www. eldiario.es/contrapoder/comisiones_verdad_america_6_336026413.html).

ICTJE (2015). "Verdad y Memoria". (Fecha de consulta: 30 de septiembre de 2015). (Disponible en https://www.ictj.org/es/our-work/transitional-justiceissues/verdad-y-memoria).

Ley No 52/2007 (2007). "Ley de Memoria Histórica del Estado Español”. (Fecha de consulta: 28 de septiembre de 2015). (Disponible en http://leymemoria. mjusticia.gob.es/cs/Satellite/LeyMemoria/es/memoria-historica-522007).

Ley No 975 (2005). "Ley de Justicia y Paz" de Colombia. (Fecha de consulta: 27 de septiembre de 2015). (Disponible en http://www.cepal.org/oig/doc/ COL2005Ley975.pdf).

NaCiones Unidas (2006). "Convención Internacional para la protección de todas las personas contra las desapariciones forzadas". Artículos 12 y 22.29 de junio de 2006. (Fecha de consulta: 27 de julio de 2015). (Disponible en http://www.cruzroja.es/dih/pdf/Convencion_Internacional_proteccion_personas_contra_desapariciones_forzadas.pdf).

NACiOnes Unidas (2015). “Día Internacional del Derecho a la Verdad en relación con las Violaciones Graves de los Derechos Humanos y de la Dignidad de sus Víctimas”. (Fecha de consulta: 26 de septiembre de 2015). (Disponible en http://www.un.org/es/events/righttotruthday/).

Naciones Unidas (2008). "El Derecho a la Verdad”, Consejo de Derechos Humanos de las Naciones Unidas. Resolución No 9/11 de 24 de septiembre de 2008. (Fecha de consulta: 27 de septiembre de 2015). (Disponible en http:// ap.ohchr.org/documents/S/HRC/resolutions/A_HRC_RES_9_11.doc). 
NAQVI, Yasmín (2006). "El derecho a la verdad en el derecho internacional: ¿̨realidad o ficción?” (Fecha de consulta: 31 de diciembre de 2015). (Disponible en https://www.icrc.org/eng/assets/files/other/irrc_862_naqvi.pdf).

OEA (2011). "Derecho a la Verdad". (Fecha de consulta: 10 de octubre de 2015). (Disponible en http://www.oas.org/es/cidh/expresion/showarticle. asp?artID=156\&lID=2).

OEA, Comisión Interamericana de Derechos Humanos, Informe No 37/00 de 13/04/2000, párrafos 152-151; 158 y 161. (Fecha de consulta: 22 de diciembre de 2015). (Disponible en https://www.cidh.oas.org/annualrep/99span/ De\%20Fondo/ElSalvador11481.htm).

Sentencia Corte IDH del caso Castillo Páez, 3 de noviembre de 1997, serie C No 34, párrafo 90. (Fecha de consulta: 23 de septiembre de 2015). (Disponible en http://www.corteidh.or.cr/docs/casos/articulos/seriec_34_esp.pdf).

Sentencia Corte IDH del caso Contreras y otros contra El Salvador, 31 de agosto de 2011, serie C No 232, párrafos 170 y 171. (Fecha de consulta: 29 de septiembre de 2015). (Disponible en http://corteidh.or.cr/docs/casos/articulos/ seriec_232_esp.pdf).

Sentencia Corte IDH del caso Myrna Mack Chang, 25 de noviembre de 2003, serie C No 101, considerando 274 y Resoluciones Nos. 6 y 11. (Fecha de consulta: 23 de septiembre de 2015). (Disponible en http://www.corteidh. or.cr/docs/casos/articulos/seriec_101_esp.pdf).

Sentencia Corte IDH del caso Trujillo Oroza, 27 de febrero de 2002, serie C No 92, párrafo 114. (Fecha de consulta: 23 de septiembre de 2015). (Disponible en http://www.corteidh.or.cr/docs/casos/articulos/Seriec_92_esp.pdf).

Sentencia Corte IDH del caso Godínez Cruz versus Honduras, 20 de enero de 1989, serie C No 5, párrafo 188. (Fecha de consulta: 27 de septiembre de 2016). (Disponible en http://www.corteidh.or.cr/docs/casos/articulos/ seriec_05_esp.pdf).

Sentencia Corte IDH, Caso González Medina y familiares versus República Dominicana, 27 de febrero de 2012, serie C No 240, párrafos 263, 264, 265 y 266. (Fecha de consulta: 23 de diciembre de 2015). (Disponible en http:// corteidh.or.cr/docs/casos/articulos/seriec_240_esp.pdf).

Sentencia Corte IDH, Caso Bulacio, 18 de septiembre de 2003, serie C No 100, párrafo 114. (Fecha de consulta: 24 de septiembre de 2015). (Disponible en http://www.corteidh.or.cr/docs/casos/articulos/seriec_100_esp.pdf).

Sentencia Corte IDH, Caso de la Masacre de La Rochela, 11 de mayo de 2007, serie C No 163, párrafo 195. (Fecha de consulta: 24 de septiembre de 2015). 
(Disponible en http://www.corteidh.or.cr/docs/casos/articulos/seriec_163_esp. pdf).

Sentencia Corte IDH, Caso Alban Cornejo y Otros, 22 de noviembre de 2007, serie C No 171, párrafo 52. (Fecha de consulta: 27 de septiembre de 2015). (Disponible en http://www.corteidh.or.cr/docs/casos/articulos/seriec_171_esp.pdf).

Sentencia Corte IDH, Caso Anzualdo Castro vs. Perú, 22 de septiembre de 2009, serie C No 202, párrafos 118 y 119. (Fecha de consulta: 17 de septiembre de 2015). (Disponible en http://www.corteidh.or.cr/docs/casos/articulos/ seriec_202_esp.pdf).

Sentencia Corte IDH, Caso Blanco Romero y Otros, 28 de noviembre de 2005, serie C No 138, párrafo 62 y voto razonado del Juez Cancado Trindade. (Fecha de consulta: 15 de septiembre de 2015). (Disponible en http://biblio. juridicas.unam.mx/libros/6/2608/5.pdf).

Sentencia Corte IDH, Caso de la Masacre de Pueblo Bello, 31 de enero de 2006, serie C No 140, párrafos 219 y 194. (Fecha de consulta: 23 de septiembre de 2015). (Disponible en http://biblio.juridicas.unam.mx/libros/6/2608/6.pdf).

Sentencia Corte IDH, Caso Comunidad de Río Negro vs. Guatemala, 4 de septiembre de 2012, serie C No 250, párrafo 194. (Fecha de consulta: 21 de septiembre de 2015). (Disponible en http://www.corteidh.or.cr/docs/casos/ articulos/seriec_250_esp.pdf).

Sentencia Corte IDH, Caso Familia Barrios con Venezuela, 24 de noviembre de 2011, C No 237, párrafo 291. (Fecha de consulta: 29 de septiembre de 2015). (Disponible en http://corteidh.or.cr/docs/casos/articulos/seriec_237_esp.pdf).

Sentencia Corte IDH, Caso Bámaca Velásquez con Guatemala, 22 de febrero de 2002, serie C 91, párrafo 77. (Fecha de consulta: 20 de septiembre de 2015). (Disponible en http://www.corteidh.or.cr/docs/casos/articulos/Seriec_91_esp. pdf).

Sentencia Corte IDH, Caso Gomes Lund y otros (Guerrilha de Araguaia) con Brasil, 24 de noviembre de 2010, serie C No 219, párrafos 201 y 211. (Fecha de consulta: 19 de septiembre de 2015). (Disponible en http://www.corteidh. or.cr/docs/casos/articulos/seriec_219_esp.pdf).

Sentencia Corte IDH caso Velásquez Rodríguez con Honduras, 29 de julio de 1988, serie C No 04, párrafo 181. (Fecha de consulta: 2 de septiembre de 2015). (Disponible en http://www.corteidh.or.cr/docs/casos/articulos/seriec_04_esp.pdf). 
Sentencia Corte IDH, Caso Zambrano Veliz y otros contra Ecuador, 4 de julio de 2007, serie C No 166, párrafo 115. (Fecha de consulta: 30 de julio de 2015). (Disponible en http://www.corteidh.or.cr/docs/casos/articulos/seriec_166_esp1.pdf).

Sentencia Corte IDH, Caso Barrios Altos contra Perú, 14 de marzo de 2001, serie C No 75, párrafo 48. (Fecha de consulta: 15 de septiembre de 2015). (Disponible en http://www.corteidh.or.cr/docs/casos/articulos/Seriec_75_esp.pdf).

Sentencia Corte IDH, Caso 19 Comerciantes, 5 de julio de 2004, Serie C No 109, párrafo 261. (Fecha de consulta: 28 de diciembre de 2015). (Disponible en http://www.corteidh.or.cr/docs/casos/articulos/seriec_109_esp.pdf).

Sentencia Corte IDH, Caso de los Hermanos Gómez Paquiyauri, 8 de julio de 2004, Serie C No 110, párrafo 230. (Fecha de consulta: 29 de diciembre de 2015). (Disponible en http://www.corteidh.or.cr/docs/casos/articulos/ seriec_110_esp.pdf).

Sentencia Corte IDH, Caso de la Comunidad Moiwana versus Surinam, 15 de junio de 2005, Serie C No 124, párrafo 204. (Fecha de consulta: 30 de diciembre de 2015). (Disponible en http://www.corteidh.or.cr/docs/casos/ articulos/seriec_124_esp1.pdf).

Sentencia Corte IDH, Caso Vargas Areco, 5 de julio de 2006, Serie C No 150, párrafo 289. (Fecha de consulta: 24 de diciembre de 2015). (Disponible en http://www.corteidh.or.cr/docs/casos/articulos/seriec_155_esp.pdf).

Sentencia Corte IDH, Caso Kawas Fernández versus Honduras, 3 de abril de 2009, Serie C No 196, párrafo 117. (Fecha de consulta: 25 de diciembre de 2015). (Disponible en http://www.corteidh.or.cr/docs/casos/articulos/ seriec_196_esp.pdf).

Sentencia Corte IDH, Caso Comunidad Campesina Santa Bárbara versus Perú, 1 de septiembre de 2015, Serie C No 299, párrafos 261 a 265. (Fecha de consulta: 2 de septiembre de 2015). (Disponible en http://www.corteidh. or.cr/docs/casos/articulos/seriec_299_esp.pdf).

Sentencia Corte IDH, Caso Rodríguez Vera y Otros versus Colombia, 14 de noviembre de 2014, Serie C No 287, párrafo 509. (Fecha de consulta: 7 de septiembre de 2015). (Disponible en http://www.corteidh.or.cr/docs/casos/ articulos/seriec_287_esp.pdf).

Sentencia Corte Constitucional de Colombia sobre Inconstitucionalidad "Marco de Justicia Transicional para el establecimiento de una paz estable y duradera”, 28 de agosto de 2013, Rol No 579/13. (Fecha de consulta: 13 de 
septiembre de 2015). (Disponible en http://www.corteconstitucional.gov.co/ RELATORIA/2013/C-579-13.htm).

Sentencia de la Corte Suprema de Chile, causa rol No 11745-11, 5 abril de 2012, Primera Sala. (Fecha de la consulta: 27 de diciembre de 2015). (Disponible en http://suprema.poderjudicial.cl/SITSUPPORWEB/DownloadFile.do?TIP_Documento=3\&TIP_Archivo $=1 \&$ COD_Opcion $=1 \& C O D$ Corte $=1 \&$ CRR_IdTramite $=1069566 \&$ CRR_IdDocumento=666029).

Sentencia Corte Suprema de la Nación Argentina (2005), Caso "Simón, Julio Héctor y otros por privación ilegítima de libertad”, Causa No 17.768 del 14 de junio de 2005. (Fecha de consulta: 25 de julio de 2015). (Disponible en http://www.desaparecidos.org/nuncamas/web/juicios/argentin/ ctesupr_20050614b.htm).

Sentencia Corte Suprema de Justicia México. "Controversia de constitucionalidad sobre artículo 57, fracción II el Código de Justicia Militar”, 14 de julio de 2011, Rol No 912/2010. (Fecha de consulta: 20 de agosto de 2015). (Disponible en http://fueromilitar.scjn.gob.mx/Resoluciones/Varios_912_2010.pdf). Sentencia Tribunal Constitucional de Perú, "Caso Genaro Villegas Namuche”, de 18 de marzo de 2004, Rol No 2488-2002. (Fecha de consulta: 25 de septiembre de 2015). (Disponible en http://www.tc.gob.pe/jurisprudencia/2004/024882002-HC.html). 